\title{
Multistimuli Responsive Dynamic Effects in a One-Dimensional Coordination Polymer
}

\author{
Bibhuti Bhusan Rath, ${ }^{* *}$ Mayank Gupta, ${ }^{\dagger}$ and Jagadese J. Vittal* \\ Department of Chemistry, National University of Singapore, Singapore 117543
}

Key words: Coordination polymer $\bullet$ photosalience $\bullet$ thermosalience $\bullet$ elastic bending $\bullet$ multistimuli response

\begin{abstract}
The development of multistimuli receptive actuators demands rational combination of suitable functionalities. Achieving such actuating properties in a single crystalline material is a challenge. In spite of several investigation on photo-, thermo- and mechano- responsive crystals, single crystalline material displaying all these effects is unknown. By a judicious combination of photoreactive 2-fluoro-4'-styrylpyridine units and flexible $\mathrm{Pb}(\mathrm{SCN})_{2}$ units, multistimuli responsive $1 \mathrm{D} \mathrm{CP}$ showing all these dynamic effects has been fabricated. Single crystals of the CP display rapid ballistic events upon UV irradiation triggered by [2+2] cycloaddition of the photoreactive ligands. In addition, macroscopic jumping, bending, splitting of the crystals were observed during both heating and cooling cycles, because of the reversible phase transition. In addition, slander crystals of the CP exhibt elastic deformation upon the application of mechanical force. With handful examples CPs showing macroscopic dynamic effects, this $\mathrm{CP}$ paves the way for designing multistimuli responsive multi-salient actuating materials.
\end{abstract}

\section{INTRODUCTION}

Emergent research on the dynamic nature of single crystals has caused a paradigm shift in the perception of crystalline materials..$^{1-3}$ In recent years, significant research activities contributed to the understanding of crystal deformation caused by stimuli induced structural perturbation. ${ }^{4}$ Inherent virtue of molecular dynamism can be translated to the crystal bulk by the instigation of an external stimulant force. Utilization of the supplied energy in the form of light, heat, pressure may result in jumping, explosion, hopping, twisting, and bending of macroscopic crystals. $^{1-3,}$, -20 Efficient energy transduction by single crystalline materials is attractive because of their dense and ordered packing. Capitalization on the actuating properties may open up avenue for their use in smart energy harvesting materials, soft robotics, artificial muscle etc.1, 21 , ${ }^{22} \mathrm{~A}$ new area of research, known as crystal adaptronics has evolved focussing on the applicability of crystalline materials. ${ }^{21}$ Multistimuli responsive actuators are superior due to their multifunctional ability in response to different stimuli. However, developing such materials needs careful integration of active functionalities that can respond to different external stimuli. In quest of developing mechanical actuators, researchers have explicitly studied photosalient effects ${ }^{23-32}$, thermosalient effects ${ }^{15}, 33-45$ and mechanical flexibility ${ }^{1,5,13,46}$ in molecular crystals by employing light, heat, and mechanical force, respectively. To date, examples of dual stimuli actuating properties in single crystals are limited. ${ }^{47-50}$ Naumov et al. reported both photo- and thermo actuated hybrid film by combining a thermosalient crystal with a photo- and thermoresponsive polymer. ${ }^{51}$ Although several reports have described photosalient and thermosalient effects in single crystalline materials individually, example of dual responsive material showing both the phenomena are rare.52, 53 In terms of multifunctional behavior, Naumov et al. have described a cocrystal responding to multiple external stimuli (heat, UV light, and mechanical pressure). ${ }^{54}$ Single crystalline material showing multistimuli responsive photosalient effects, thermosalient effects and mechanical flexibility is unknown so far.

Recent investigation on mechanically compliant coordination polymers (CPs) has given them immense possibility to join the organic league as potential actuators. ${ }^{11,29,47,55,56}$ Handful examples of CPs showing macroscopic dynamic effects when subjected to external stimuli22, suggest the need for further research. Very few CPs have shown photosalient, thermosalient, and mechanical properties individually. ${ }^{22}$ In general, CP showing multistimuli actuation is scarce. ${ }^{47,50}$ So, this gives the opportunity for the development of a single crystalline $\mathrm{CP}$ having the capability to be actuated by light, heat and mechanical force.

Herein, we disclose a $1 \mathrm{D} \mathrm{CP}$ of $\mathrm{Pb}(\mathrm{II})\left[\mathrm{Pb}(\mathrm{SCN})_{2}(2 \mathrm{~F}\right.$ spy)2], 1, which shows multistimuli responsive actuation properties. Rational combination of a photoreactive $2 \mathrm{~F}$-spy ligand with flexible $\mathrm{Pb}_{3}(\mathrm{SCN})_{3}$ units enables the $\mathrm{CP}$ to show photosalient, thermosalient, and mechanically flexible properties when stimulated by light, heat, and mechanical force, respectively. Single crystals show violent ballistic events upon UV irradiation due to [2+2] cycloaddition of 2Fspy ligands. Apart from this, the reversible thermosalient effect showing macroscopic jumping, bending, splitting was observed on both heating and cooling cycles owing to the reversible isosymmetric phase transition. The 
thermosalient effect was preceded by anisotropic thermal expansion, which facilitated the phase transition. Salient effects were caused by the stress accumulated due to the stimuli induced structural reconfiguration. In addition, slander crystals also exhibit mechanical flexibility. We are not aware of the concurrent occurrence of all these stimuli responsive macroscopic dynamic effects in a single crystalline material before.

\section{RESULTS AND DISCUSSION}

Structural Analysis. Slow evaporation of a DMF solution containing $\mathrm{Pb}(\mathrm{SCN})_{2}$ and $2 \mathrm{~F}$-spy at a $1: 2$ ratio produced single crystals of the $1 \mathrm{D} \mathrm{CP}\left[\mathrm{Pb}(\mathrm{SCN})_{2}(2 \mathrm{~F}-\mathrm{spy})_{2}\right]$, 1 within a few days. The compound crystallized in orthorhombic space group $P 2{ }_{1} 2_{1} 2_{1}$ with $Z=4$. The asymmetric unit constitutes the formula unit of the compound (Figure $1 \mathrm{a}$ ). The $\mathrm{Pb}(\mathrm{II})$ atom attains distorted pentagonal bipyramidal geometry by coordinating to three $\mathrm{S}$ atoms and two $\mathrm{N}$ atoms of SCN ligands at equatorial positions while two $\mathrm{N}$ atoms of $2 \mathrm{~F}$-spy ligands occupy the apical positions. Two of the $\mathrm{S}$ atoms bridge via $\mu_{2}$ mode while other $\mathrm{S}$ atom and two $\mathrm{N}$ atoms bridge via $\mu_{1}$ mode. The Pb-S distances, 3.041(1), 3.0198(9) and 3.188(1) A fall well below the sum of the Van der Waals radii (3.82 $\AA$ ) of $\mathrm{Pb}$ and $\mathrm{S}$. One SCN is bridging the $\mathrm{Pb}(\mathrm{II})$ atoms to form a zigzag polymer. Another SCN ligand bridges alternating $\mathrm{Pb}(\mathrm{II})$ atoms resulting in the formation of 12-membered $\mathrm{Pb}_{3}(\mathrm{SCN})_{3}$ rings which are fused together and extended along the $a$-axis like a highly corrugated ribbon-like $1 \mathrm{D}$ motif (Figure 1b). The $\mathrm{Pb}-\mathrm{S}-\mathrm{C}$ angles are 102.8(1) and $110.4(1)^{\circ}$. Each $\mathrm{Pb} 1$ atom acts as a vertex for three rings. The distance $5.872 \AA$ between the alternating $\mathrm{Pb} \cdots \mathrm{Pb}$ corresponds to the $a$-axis of the cell. The photoreactive $2 \mathrm{~F}$ spy ligands are projected along the $b$-axis. a)

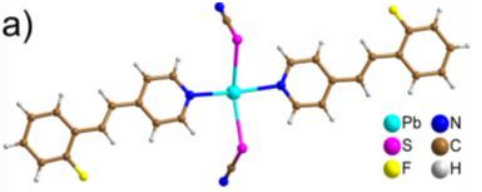

C)

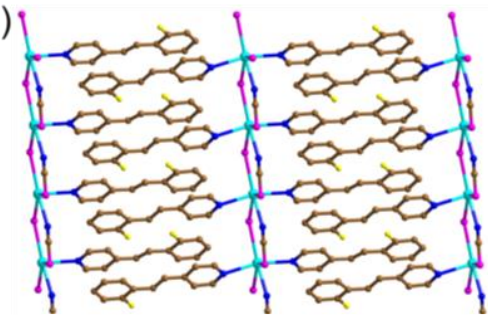

b)

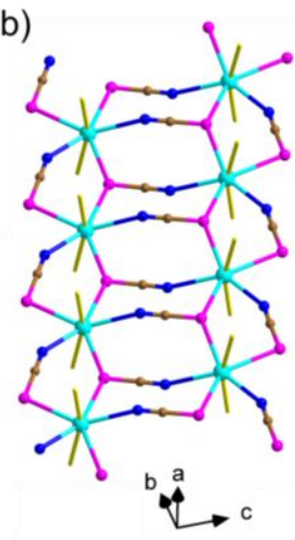

Figure 1 (a) Asymmetric unit of $\mathbf{1}$ showing selected atom labels, (b) coordination environment around $\mathrm{Pb}$ (II) atoms, with corrugated ribbon-like 1D motif (yellow rods represent 2F-spy ligands) and (c) the packing of 1D chains in $\mathbf{1}$.

Adjacent corrugated ribbon-like $\left[\mathrm{Pb}(\mathrm{SCN})_{2}\right]$ polymers are packed in such a way that the neighboring 2F-spy ligands are disposed very closely in a head-to-tail manner. The center-to-center distances between the pyridyl and Fphenyl groups, 3.657 and $3.870 \AA$ enforces close $\pi \cdots \pi$ interactions between the 2F-spy pairs (Figure 1c). This enables the olefin bond pairs to align in parallel with a separation of $3.762 \AA$, which falls well below Schmidt's topochemical criteria ${ }^{57}$ for the [2+2] photocycloaddition reaction. This orientation is possibly assisted by the presence of strong $\mathrm{C}-\mathrm{H} \cdots \mathrm{F}$ interactions between the neighboring chains, facilitating interchain network throughout the crystal. When a complete formation of cyclobutane ring occurs, the resultant photoproduct is expected to be a 2D CP formed in the $a b$ plane which is perpendicular to the $c$-axis.

Photosalient effects. Irradiation experiments of single crystals of 1 were carried out using MAX-350 with a $300 \mathrm{~W}$ xenon light source under a microscope furnished with a high-quality camera. Various dimensions of crystals showed photomechanical effects such as jumping, bending, splitting immediately after UV illumination (Figure 2 and Video S1).

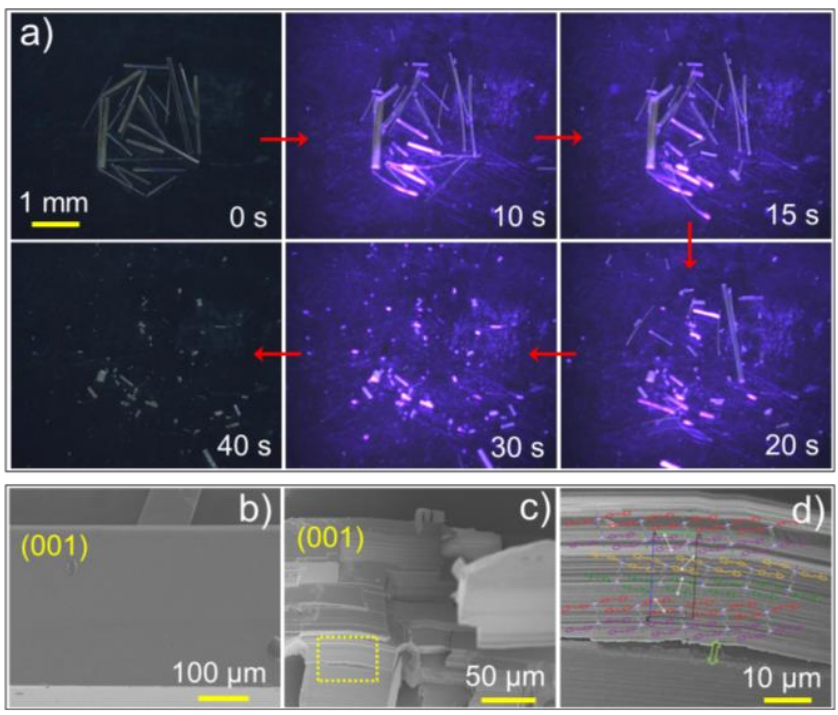

Figure 2. (a) Optical images of single crystals of $\mathbf{1}$ showing violent photosalient effects. SEM images of crystal (b) before and (c, d) after 5s UV irradiation.

In general, macroscopic effects are resultant of the strain developed across the crystal, which in turn depends upon the microscopic strain tensor and crystal dimension. ${ }^{1}$ $25 \mathrm{~s}$ of UV irradiation induced bending in some crystals, mostly of smaller width for a small time. Continuous stress relaxation with further UV irradiation results in violent jumping, hopping, and splitting of the crystals, collectively known as the photosalient effects. Crystals danced under UV light during $40 \mathrm{~s}$ irradiation, resulting in splintering of crystals. Fragmented portions of the crystals were left on the glass slide while most of them jumped away from the visual field of the microscope.

The photosalient effect is still an uncommon phenomenon in the case of $\mathrm{CPs}^{29,} 58$ even though it is reported for several organic crystals and coordination complexes. The observed photosalient effect could be the consequence of dimerization of photoreactive 2F-spy ligands, as seen in the examples reported previously. ${ }^{24,26}{ }^{1} \mathrm{H}$ NMR spectral analysis of residual crystals was also suggestive of this assumption. A comparison between ${ }^{1} \mathrm{H}$ NMR spectrum of $\mathbf{1}$ and that of the irradiated crystals reveals a decrease in the signal of pyridyl protons of $2 \mathrm{~F}$-spy at $8.57 \mathrm{ppm}$ with the evolution of new peaks at $8.33 \mathrm{ppm}$ and $4.71 \mathrm{ppm}$. The new peaks can be ascribed to the formation of a dimer rctt-1,3-bis(4-pyridyl)-2,4-bis(2'fluoro-phenyl)cyclobutane ( $r c t t-2 \mathrm{~F}$-ppcb), where the peaks at $8.34 \mathrm{ppm}$ and $4.61 \mathrm{ppm}$ evolve due to the pyridyl and cyclobutane protons of $r c t$-2F-ppcb respectively (Figure 3). Integration of the pyridyl peaks indicates the formation of $68 \%$ of the dimer after the photosalient effects (Figure 3). Similar observation has been made in reported examples 
showing PS effects with partial photoconversion. 24, 26, 30, 31, 50, 58 This is because of the stress accumulated in the crystal due to heterogenous product distribution and its release at the interface of two phases or defects in the crystal. ${ }^{58}$

Rapid release of strain energy results in the mechanical effects of the crystals causing them to jump, split or hop. Unlike our prior work, ${ }^{58}$ a conclusive evidence based on single crystal structure could not be obtained due to deterioration in single crystal integrity. Partial dimerized crystals were not useful either as they diffracted poorly. Continual UV irradiation till $100 \%$ photoconversion resulted in the formation of a less crystalline solid (Figure S1). Sometimes, photosalient crystals lose crystallinity and end up as amorphous compounds after complete dimerization. ${ }^{26}$ This is on account of the damage to the long range order of the crystal after a sudden volume expansion. Fast mechanical response of the crystals showing ballistic motions and fragmentation under UV light is indicative of this phenomenon.

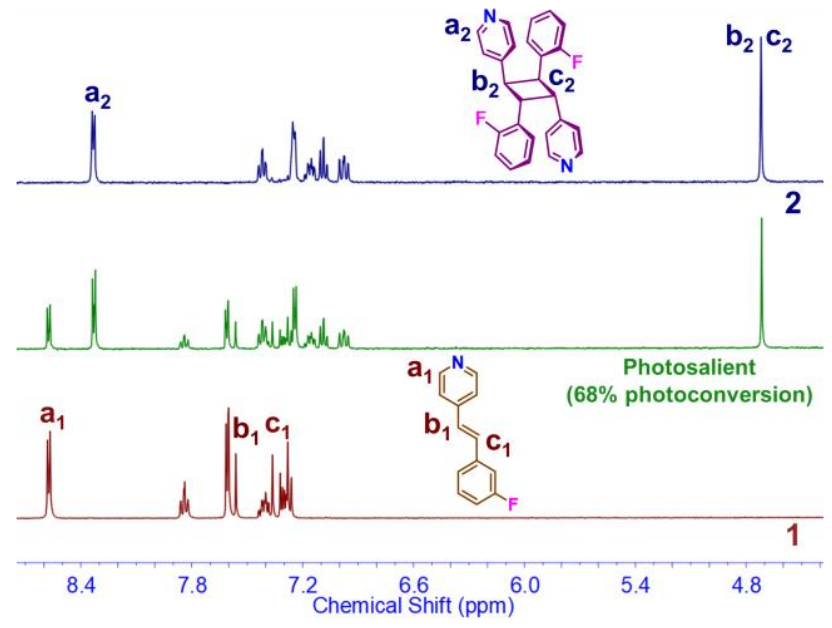

Figure 3. ${ }^{1} \mathrm{H}$ NMR spectra of $\mathbf{1}$, post photosalient $\mathbf{1}$ and the dimerized CP 2 . Only selective proton peaks are assigned.

Different mechanical response was studied in crystals of two different habits (i.e., dimensions) under a lower intensity UV light. At first, crystals placed in parallel showed bending away from the light direction. Later, crystal of bigger width split across the (100) plane while the crystal with smaller width sustained such splitting to result a bent crystal. Differential product formation on the irradiated surface generates different strain gradient across the crystal surfaces. Sustaining the strain could result in bending, while beyond a threshold value it could lead to fragmentation. ${ }^{2}$ This is dependent on the surface area of the irradiated face. Reversal of the light direction results in straightening the bent crystal due to the product formation on the previously unreacted surface. Figure S13 and Video S2 depict light direction dependent photomechanical behavior of two single crystals.

Attempts to get the single crystal structure of the dimerized 2D CP by recrystallization were unsuccessful. Poor crystallinity of the photodimerized compound did not result in the formation of single crystals. However, we could successfully isolate the single crystal structure of an elusive dimerized ligand $r c t$ - $2 \mathrm{~F}$-ppcb. The single crystal structure indeed confirms the head-to-tail dimerization of 2F-spy ligands in the 1D CP (Figure S9). This would prompt the transformation of the $1 \mathrm{D}$ CP to a 2D CP accompanied by the photosalient effect. A direct comparison between the $2 \mathrm{~F}$ spy ligands in $\mathbf{1}$ and the isolated rctt-2F-ppcb may not be accurate, but such comparison may shed some light on the strain developed due to the photodimerization. The distance between the olefin bonds reduced from $3.762 \AA$ to 1.563(5) A after the formation of a cyclobutane ring, causing a strained structure which further increased the distance between the outermost $\mathrm{N}$ and $\mathrm{C}$ atoms (Figure S9). Cycloaddition exerts force on (001) at an angle $60^{\circ}$ from four different layers of aligned ligands. Due to such orientation, large amount of stress is generated, and multiple domains may form within the crystals (Figure S8). Thus, the single crystals of $\mathbf{1}$ could not withstand the strain developed during the photodimerization, leading to photosalient effects.

Thermosalient effects. Apart from its fascinating photosalient effect due to a photoreactive ligand, the flexible structural feature enables $\mathbf{1}$ to be mechanically active upon heating/cooling. At first, single crystals were subjected to investigation by differential scanning calorimetry (DSC) at different heating/cooling rates. Heating at a rate of $5 \mathrm{~K} \mathrm{~min}^{-1}$ resulted in an endothermic peak between 401 and $410 \mathrm{~K}$, which marks a phase transition (phase I to phase II). The phase transition was possibly accompanied by mechanical movements of crystals in the pan generating a zigzag pattern in the DSC curve (Figure 4). This typical patten of thermosalient crystals has been well reported in the literature. ${ }^{33,34,41-43,59}$ Transition enthalpy $(\Delta H)$ for the endotherm was found out to be -3.61 $\mathrm{J} \mathrm{g}^{-1}$. This phase transition was reversible on cooling, as clearly seen from the exothermic peaks between 399 and $386 \mathrm{~K}$, with similar zigzag pattern. This is indicative of the reversal of phase II to phase I $\left(\Delta \mathrm{H}=-3.58 \mathrm{~J} \mathrm{~g}^{-1}\right)$ accompanied by the thermosalient effect (Figure 4). Example of reversible thermosalience in CPs is scarce in the literature, with only one report so far. ${ }^{60}$ The reversible thermosalience could be repeated for three consecutive cycles in the DSC curves after which the zigzag pattern smoothened, possibly as a result of the mechanical fatigue in the crystals. Even though powder samples did show the reversible phase change, the zigzag pattern was absent in the DSC curve (Figure S4) as observed in previous cases. ${ }^{60}$

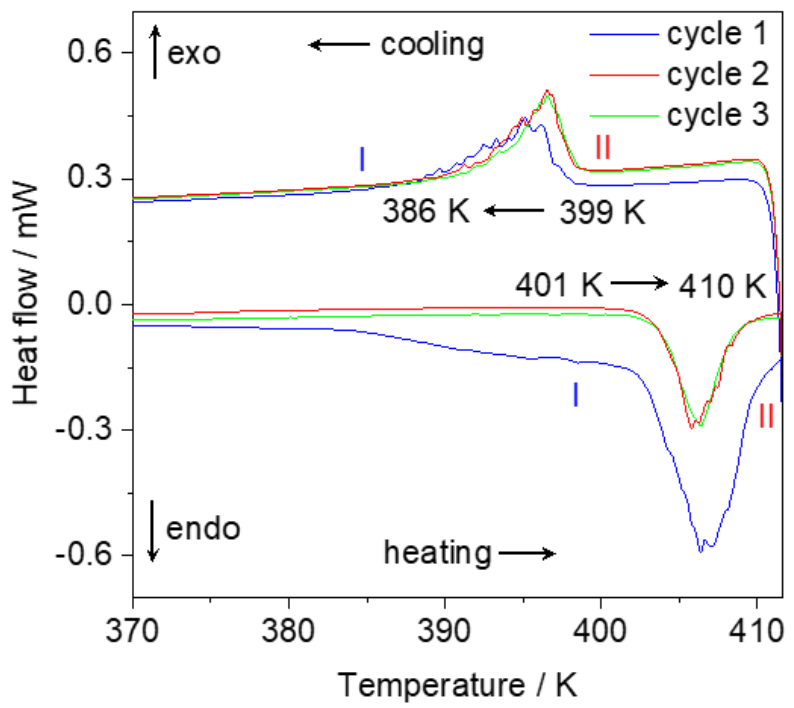

Figure 4. DSC curves of the single crystals of $\mathbf{1}$ for three consecutive heating-cooling cycles at a heating/cooling rate 5 $\mathrm{K}_{\text {min }^{-1}}$. 

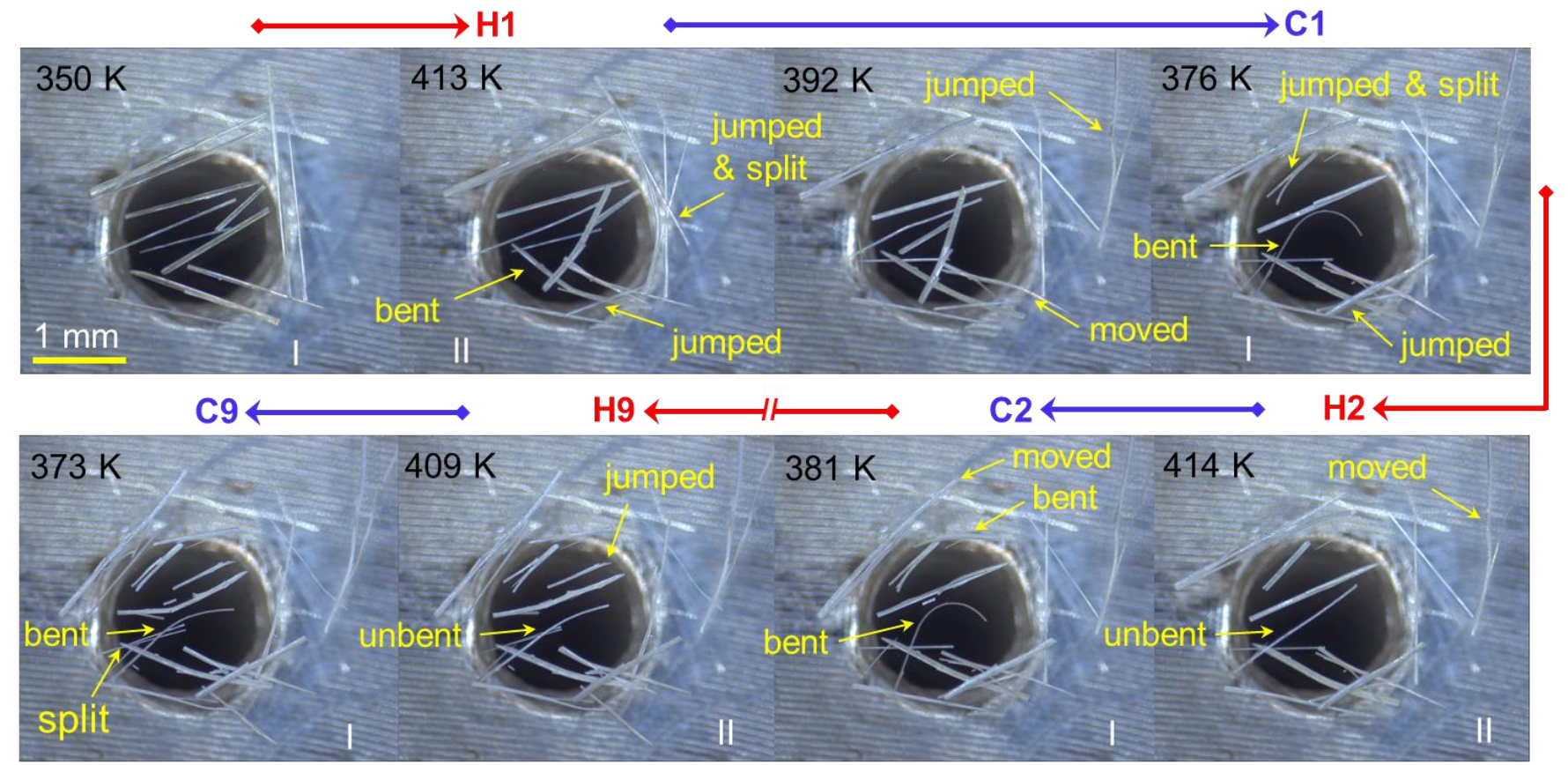

Figure 5. Hot stage microscopy images of single crystals of 1 showing the thermomechanical motilities during nine heating-cooling cycles. The heating/cooling rate was $5 \mathrm{~K} \mathrm{~min}^{-1}$. Video S3 is provided corresponding to Figure 5.

Heat induced mechanical motility of single crystals of $\mathbf{1}$ was studied by hot stage microscopy. When heated from room temperature to $399 \mathrm{~K}$, crystals show impressive thermosalient effect due to the phase change as spotted in the DSC experiments. Peculiar jumping, splitting, bending of the crystals were observed during this transition to high temperature phase (phase II). The thermosalient effect was also pronounced on cooling, due to the reversible phase transition (phase II to phase I). Mechanical motility such as jumping, splitting was prevalent like the heating cycle (Figure 5 and Video S3). Most interestingly, previously bent crystals during the heating cycle underwent straightening on cooling. This could be repeated for several heatingcooling cycles when a crystal underwent bending and straightening until mechanical fatigue. After nine consecutive heating-cooling cycles, remains of split and bent crystals were left (Figure 5 and Video S3). Contractionexpansion along the crystal length was visible for the bigger crystals which showed fewer mechanical movements. During the $1^{\text {st }}$ heating, the propagation of phase II over phase I was clearly observed and multiphase crystal persisted for a very small period, which is indicative of a martensitic phase transition ${ }^{60}$ (Figure S14 and Video S4). Crystals expanded and became opaque on subsequent cooling. So, it was difficult to observe the propagation of phase I over phase II. Consecutive heating-cooling cycles resulted in multiple splitting of crystals (Figure S14 and Video S4).

In general, the thermosalient effect is often preceded by a large anisotropic thermal expansion in the crystal lattice. ${ }^{33-35}, 41-43,47,59$ Variable temperature SCXRD data between $173 \mathrm{~K}$ and $393 \mathrm{~K}$ revealed expansion along the crystal axes. Uneven expansion causes anisotropy in the overall thermal expansion. The thermal expansion coefficients were calculated by employing PASCal program. ${ }^{61} \mathrm{~A}$ single crystal mounted on a glass fiber shows positive thermal expansion along all the principal axes $X_{1}$, $X_{2}, X_{3}$ which coincide with the cell axes $b, a$, and $c$ respectively. Smaller positive thermal expansions occur along the principal $X_{1}$-axis [010] and $X_{2}$-axis [100] with expansion coefficients of $11.8575 \times 10^{-6} \mathrm{~K}^{-1}$ and $38.6900 \times$ $10^{-6} \mathrm{~K}^{-1}$ respectively, while relatively large thermal expansion occurs along the $X_{3}$-axis [001] with expansion coefficients of $109.0696 \times 10^{-6} \mathrm{~K}^{-1}$. Positive thermal expansions along all the principal axes result in a positive volumetric expansion, $\alpha_{V}=161.9953 \times 10^{-6} \mathrm{~K}^{-1}$, representing an increase of $\sim 3.6 \%$ in the overall volume. More details are given in supporting information Figure S15-S17 and Table S3-S4.

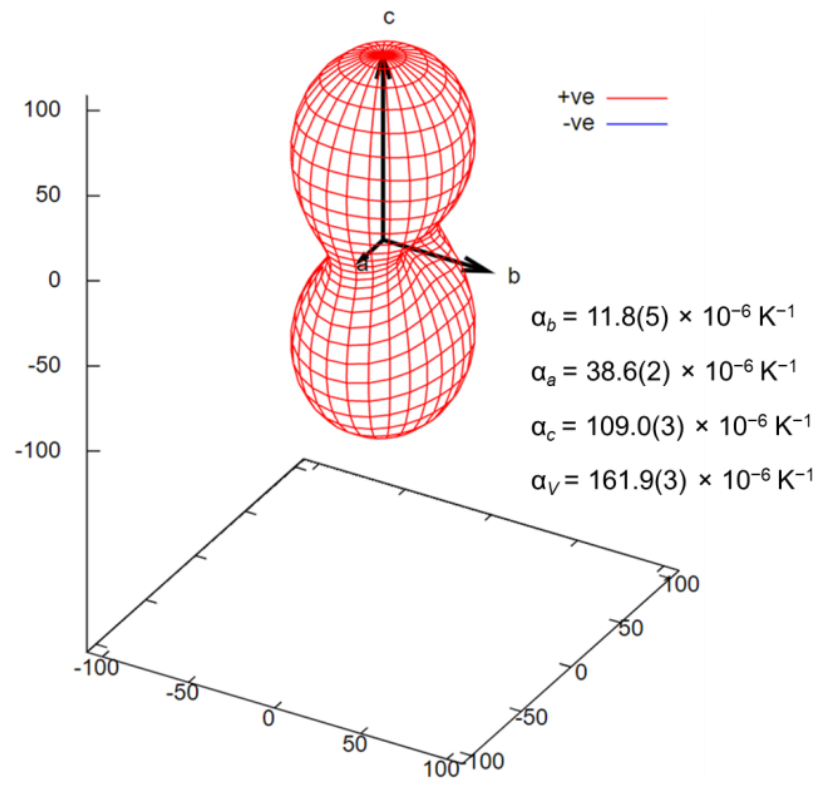

Figure 6. Triaxial positive thermal expansion coefficients and plot of the expansivity indicatrices of $\mathbf{1}$ calculated using the PASCal software on heating from $173 \mathrm{~K}$ to $393 \mathrm{~K}$.

An isosymmetric phase transition occurs at $408 \mathrm{~K}$, maintaining the same space group which is prevalent in most of the thermosalient crystals. The anisotropic thermal 
expansion preceding the phase transition prepares the crystal to undergo transformation to the high temperature phase (phase II). Several attempts to solve the single crystal structure after the phase transition were unsuccessful, as the single crystallinity was lost during the SCXRD measurements. However, using the diffraction pattern before crystal deterioration, cell data of the high temperature phase could be obtained. During the phase transition the $a$-axis corresponding to the crystal length decreases by $2.24 \%$ resulting in the observed contraction along the major crystal axis. On the other hand, $b$-axis decreases by $0.1 \%$ while the $c$-axis shows $6.27 \%$ increment. Highly anisotropic change in the cell parameters within a short period of time results in $4.42 \%$ increment in the cell volume, which accumulates stress that is overwhelming for the crystal. The stress gets released in terms of macroscopic mechanical motility of the bulk crystals, which is also dependent on the crystal morphology. The largest crystal face corresponds to the (001) plane and the crystal expands perpendicular to this face i.e., along the $c$-axis on heating, while contracts along the $a$-axis. Macroscopic dynamic effects like bending or splitting are dependent on the anisotropic strain during heating or cooling. Orientational reconfiguration in the unit cell at a molecular level control these visual outcomes. Bending along the major crystal axis occurs when a gradient develops between two faces due to differential contraction. On cooling, contracted 1D chains return to their original configuration resulting in straightening of the bent crystal. However, larger crystals with bigger width could not undergo bending due to lack of flexibility. They mostly show splitting and jumping during both heating and cooling cycles. SEM images of $\mathbf{1}$ before and after the thermosalient effect show the crystal splitting due to orthogonal elongation and contraction (Figure 7). The exerted force results in splitting mostly parallel to (001) plane. Reversibility in the anisotropic reconfiguration is the key for achieving thermosalient effect on both heating and cooling cycles. ${ }^{60}$

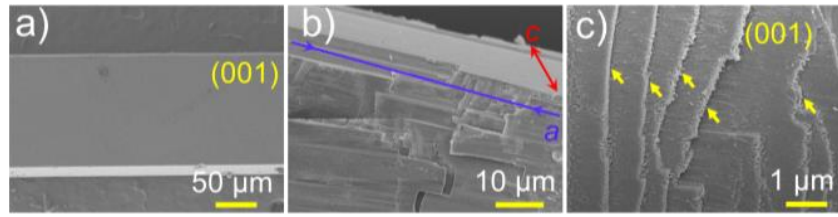

Figure 7. SEM images of single crystal of 1 (a) before and (b, c) after one heating-cooling cycle.

Mechanical Bending. Crystal bending observed during both photosalient and thermosalient experiments prompted us to study the effect of mechanical force on crystal deformation in $\mathbf{1}$. Thinner crystals of $\mathbf{1}$ were synthesized using a mixture of DMF and MeCN as crystallization solvent. Elastic deformation was observed in slander crystal of dimension (3.9 $\mathrm{mm} \times 25 \mu \mathrm{m} \times 16 \mu \mathrm{m})$ when a mechanical force was applied on the (001) plane (Figure 8 and Video S5). The crystal underwent considerable bending along the longest crystallographic face i.e., (001) plane to form an arc and returned to the original configuration upon removal of the applied force. Adjacent 1D corrugated chains propagating along the $a$-axis (crystal length) are interconnected by $\pi-\pi$ and $\mathrm{C}-\mathrm{H} \cdots \mathrm{F}$ interactions forming a $2 \mathrm{D}$ supramolecular structure in the $a b$ plane. The flexibility of the $\mathrm{Pb}_{3}(\mathrm{SCN})_{3}$ units (Figure S11) help in accommodating the stress developed due to application of the mechanical force, which is further assisted by the presence of $\mathrm{C}-\mathrm{H} \cdots \mathrm{H}-\mathrm{C}$ and $\mathrm{C}-\mathrm{H} \cdots \mathrm{S}$ interaction between the chains (Table S2). It is important to note that we could observe bending only in thinner crystals. Similar cell parameters after multiple bending experiments suggest the reversibility of the reconfiguration upon the removal of the mechanical force. The role of slip planes for elastic deformation has been contradicted previously. ${ }^{9}$ Recently, reports on mechanical flexibility of CPs shows growing interest of investigation on this research area. ${ }^{22}$ However, crystalline materials showing multistimuli responsive dynamic properties are very rare. This CP is first such material showing photosalient, thermosalient and mechanical flexible properties in a single crystalline material.

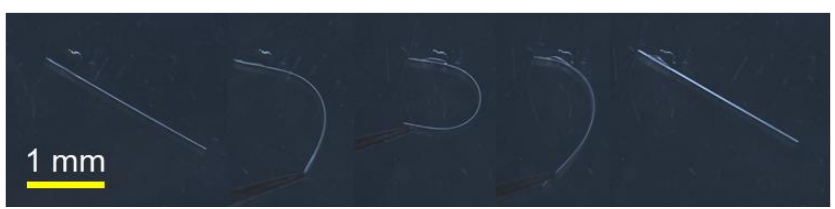

Figure 8. Mechanical force induced elastic deformation in a single crystal of $\mathbf{1}$.

\section{CONCLUSION}

Despite several literature reports on the photosalient effects, thermosalient effects and mechanical flexibility separately, concurrent occurrence of these phenomena is unknown in same single crystalline material. Here we put forward a $1 \mathrm{D} \mathrm{CP}$ of $\mathrm{Pb}(\mathrm{II})$ containing bridging SCN ligands and photoreactive 2F-spy ligands, which shows photo and heat responsive salient effects (multi-salient behavior) and macroscopic dynamism due to mechanical force. UV induced [2+2] cycloaddition reaction of $2 \mathrm{~F}$-spy ligands results in the transformation of the 1D CP 1 to a dimerized 2D structure. Coexisting reactant and product phase cause phase heterometry in the crystal in addition to the stress generated due to structural change. During the short time available for stress relaxation, the accumulated strain reaches beyond a threshold value resulting in ballistic events of crystals. Although single crystal structure of the dimerized 2D CP could not be obtained, the dimerized ligand rctt-2F-ppcb was crystalized. Apart from the photosalient effect, flexibility of $\mathrm{Pb}(\mathrm{SCN})_{2}$ units allowed the $\mathrm{CP}$ to undergo reversible reconfiguration upon heating/cooling. Abrupt anisotropic changes in the cell parameters during the isosymmetric phase transitions generated strain, that translated into macroscopic mechanical effects like jumping, splitting, and bending. The reversible thermosalient effect was preceded by anisotropic thermal expansion which paved the way for a first order phase transition. Further, slander crystals show elastic deformation upon the application of an external force, which is related to the flexibility of $1 \mathrm{D}$ chains propagating along the crystal length. In pursuit of multifunctional and multi-salient materials, this 1D CP opens avenue for the development of multistimuli actuators by rational combination of responsive functionalities.

\section{EXPERIMETAL SECTION}

Materials. Lead thiocyanate $\left\{\mathrm{Pb}(\mathrm{SCN})_{2}, 99 \%\right\}, \mathrm{N}, \mathrm{N}-$ dimethylformamide (DMF, 99.8\%) and acetonitrile (MeCN, 99.8\%) were purchased from Sigma Aldrich and used without purification. $2 \mathrm{~F}$-spy was synthesized according to a reported literature. ${ }^{62}$ 
Crystallization of $\left[\mathrm{Pb}(\mathrm{SCN})_{2}(2 \mathrm{~F}-\mathrm{spy})_{2}\right], 1$. Slow evaporation of a DMF solution containing $\mathrm{Pb}(\mathrm{SCN})_{2}(16.1$ $\mathrm{mg}, 0.05 \mathrm{mmol}$ ) and $2 \mathrm{~F}$-spy (20 $\mathrm{mg}, 0.1 \mathrm{mmol}$ ) at a $1: 2$ ratio resulted diffraction quality colourless rod-shaped single crystals of 1 within a few days.

General Characterizations. Powder X-ray diffraction (PXRD) analyses were performed on a Bruker D8 Advance powder X-ray diffractometer with graphite monochromatized $\mathrm{Cu}-\mathrm{K}_{\alpha}$ radiation $(\lambda=1.54056 \AA)$ at $\mathrm{RT}$ (298 K). ${ }^{1} \mathrm{H}$ NMR spectra were recorded on a $400 \mathrm{MHz}$ Bruker Avance 400 FT NMR spectrometer with TMS as an internal reference in DMSO- $d_{6}$ solution. Thermogravimetric analysis (TGA) was performed under nitrogen atmosphere with a heating rate of $5 \mathrm{~K} \mathrm{~min}^{-1}$ on a TA instruments Trios V3.1 thermogravimetric analyzer. Differential scanning calorimetry (DSC) experiments were performed in a Mettler Toledo differential scanning calorimeter equipped with a liquid nitrogen cooling units (TC100) under nitrogen gas atmosphere. Single crystals or powder samples were placed in a standard aluminium pan crimped with a cover and scanned at heating/cooling rate of $5 \mathrm{~K} \mathrm{~min}^{-1}$ in the temperature range 370 - $415 \mathrm{~K}$ for several cycles. The FTIR spectra were recorded using Varian Excalibur 3100 spectrometer with $\mathrm{KBr}$ pellets. JEOL JSM-6701F Field Emission Scanning Electron Microscope (FESEM) was used for SEM images. The elemental analyses $(\mathrm{C}, \mathrm{H}, \mathrm{N})$ were carried out by using ElementarVario Micro Cube instrument.

Single Crystal XRD. The SCXRD intensity data for 1 was collected at $\mathrm{T}=100 \mathrm{~K}$ and $393 \mathrm{~K}$, using a four circle goniometer with Kappa geometry and Bruker AXS D8 Venture Single Crystal X-ray Diffractometer equipped with a Photon 100 CMOS active pixel sensor detector. Variable temperature Single crystal XRD data were collected by mounting a single crystal on a glass fiber with the help of epoxy glue. APEX3 software package was used for data collection, data reduction, and absorption correction. All calculations for structure determination were carried out using the SHELXTL package. ${ }^{63}$

Photosalient effects. Experiments relating to photosalient effects were conducted by irradiating good quality single crystals of 1 with UV light ( $360 \mathrm{~nm}$ ) using Xesource using MAX-350 optical photoreactor under a microscope equipped with a high-quality camera for capturing videos and photos.

Thermosalient effects. Thermosalient effects were visually investigated under a heating/cooling stage microscopy set up. Heating/cooling rates were monitored by JHC $10002 \mathrm{~L}$ to observe the temperature changes of the samples. The samples were heated from room temperature $295 \mathrm{~K}$ to $415 \mathrm{~K}$ and then cooled to $377 \mathrm{~K}$ at the same rate for observing the thermosalient effects.

\section{ASSOCIATED CONTENT}

\section{Supporting Information.}

Experimental details, crystallographic data, PXRD, TGA, VTSCXRD data, optical microscopic images, (PDF)

Crystallographic data in cif format (CIF)

Video S1: Photosalient effects

Video S2: Light direction dependant bending

Video S3: Thermosalient effects

Video S4: Thermosalient crystal splitting
Video S5: Mechanical bending

\section{AUTHOR INFORMATION}

\section{Corresponding Authors}

* Bibhuti Bhusan Rath - Department of Chemistry, National University of Singapore, Singapore 117543 (ORCID: 0000-00025323-6936) email: bbrath@u.nus.edu

* Jagadese J. Vittal - Department of Chemistry, National University of Singapore, Singapore 117543 (ORCID: 0000-00018302-0733) email: ЏVittal@nus.edu.sg

Author

Mayank Gupta - Department of Chemistry, National University of Singapore, Singapore 117543

Author Contributions

$\dagger$ Both authors contributed equally.

Notes

The authors declare no competing financial interest.

\section{ACKNOWLEDGMENT}

This work was financially supported by the Ministry of Education, Singapore (Grant No. Tier 1 R-143-000-B13-114). We acknowledge the help of Geok Kheng Tan for collecting the single crystal X-ray intensity data.

\section{REFERENCES}

1. Naumov, P.; Karothu, D. P.; Ahmed, E.; Catalano, L.; Commins, P.; Mahmoud Halabi, J.; Al-Handawi, M. B.; Li, L., The Rise of the Dynamic Crystals. J. Am. Chem. Soc. 2020, 142 (31), 13256-13272.

2. Naumov, P. e.; Chizhik, S.; Panda, M. K.; Nath, N. K.; Boldyreva, E., Mechanically responsive molecular crystals. Chem. Rev. 2015, 115 (22), 12440-12490.

$3 . \quad$ Commins, P.; Desta, I. T.; Karothu, D. P.; Panda, M. K.; Naumov, P., Crystals on the move: mechanical effects in dynamic solids. Chem. Commun. 2016, 52 (97), 13941-13954.

4. Sato, 0., Dynamic molecular crystals with switchable physical properties. Nat. Chem. 2016, 8 (7), 644-656.

5. Saha, S.; Mishra, M. K.; Reddy, C. M.; Desiraju, G. R., From Molecules to Interactions to Crystal Engineering: Mechanical Properties of Organic Solids. Acc. Chem. Res. 2018, 51 (11), 29572967.

6. Koshima, H.; Ojima, N.; Uchimoto, H., Mechanical motion of azobenzene crystals upon photoirradiation. J. Am. Chem. Soc. 2009, 131 (20), 6890-6891.

7. $\quad$ Bushuyev, O. S.; Tomberg, A.; Friščić, T.; Barrett, C. J., Shaping crystals with light: crystal-to-crystal isomerization and photomechanical effect in fluorinated azobenzenes. J. Am. Chem. Soc 2013, 135 (34), 12556-12559.

8. Zhu, L.; Al-Kaysi, R. O.; Bardeen, C. J., Reversible photoinduced twisting of molecular crystal microribbons. J. Am. Chem. Soc. 2011, 133 (32), 12569-12575.

9. Worthy, A.; Grosjean, A.; Pfrunder, M. C.; Xu, Y.; Yan, C.; Edwards, G.; Clegg, J. K.; McMurtrie, J. C., Atomic resolution of structural changes in elastic crystals of copper(II) acetylacetonate. Nat. Chem. 2018, 10 (1), 65-69.

10. Chizhik, S.; Sidelnikov, A.; Zakharov, B.; Naumov, P.; Boldyreva, E., Quantification of photoinduced bending of dynamic molecular crystals: from macroscopic strain to kinetic constants and activation energies. Chem. Sci. 2018, 9 (8), 2319-2335.

11. Bhattacharya, B.; Michalchuk, A. A. L.; Silbernagl, D.; Rautenberg, M.; Schmid, T.; Feiler, T.; Reimann, K.; Ghalgaoui, A.; Sturm, H.; Paulus, B.; Emmerling, F., A Mechanistic Perspective on Plastically Flexible Coordination Polymers. Angew. Chem. Int. Ed. 2020, 59 (14), 5557-5561. 
12. Reddy, C. M.; Gundakaram, R. C.; Basavoju, S.; Kirchner, M. T.; Padmanabhan, K. A.; Desiraju, G. R., Structural basis for bending of organic crystals. Chem. Commun. 2005, (31), 3945-7.

13. Das, S.; Mondal, A.; Reddy, C. M., Harnessing molecular rotations in plastic crystals: a holistic view for crystal engineering of adaptive soft materials. Chem. Soc. Rev. 2020, 49 (24), 88788896.

14. Park, S. K.; Diao, Y., Martensitic transition in molecular crystals for dynamic functional materials. Chem. Soc. Rev. 2020, 49 (22), 8287-8314.

15. Khalil, A.; Karothu, D. P.; Naumov, P. e., Direct quantification of rapid and efficient single-stroke actuation by a martensitic transition in a thermosalient crystal. J. Am. Chem. Soc. 2019, 141 (8), 3371-3375.

16. Saha, S.; Desiraju, G. R., Crystal engineering of handtwisted helical crystals. J. Am. Chem. Soc. 2017, 139 (5), 1975-1983.

17. Thomas, S. P.; Shi, M. W.; Koutsantonis, G. A.; Jayatilaka, D.; Edwards, A. J.; Spackman, M. A., The Elusive Structural Origin of Plastic Bending in Dimethyl Sulfone Crystals with Quasiisotropic Crystal Packing. Angew. Chem. Int. Ed. 2017, 56 (29), 8468-8472.

18. Liu, H.; Bian, Z.; Cheng, Q.; Lan, L.; Wang, Y.; Zhang, H., Controllably realizing elastic/plastic bending based on a roomtemperature phosphorescent waveguiding organic crystal. Chem. Sci. 2019, 10 (1), 227-232.

19. Hayashi, S.; Yamamoto, S. y.; Takeuchi, D.; Ie, Y.; Takagi, K., Creating Elastic Organic Crystals of $\pi$-Conjugated Molecules with Bending Mechanofluorochromism and Flexible Optical Waveguide. Angew. Chem. Int. Ed. 2018, 57 (52), 17002-17008.

20. Mir, S. H.; Takasaki, Y.; Engel, E. R.; Takamizawa, S., Ferroelasticity in an organic crystal: A macroscopic and molecular level study. Angew. Chem. Int. Ed. 2017, 56 (50), 15882-15885.

21. Ahmed, E.; Karothu, D. P.; Naumov, P., Crystal Adaptronics: Mechanically Reconfigurable Elastic and Superelastic Molecular Crystals. Angew. Chem. Int. Ed. 2018, 57 (29), 88378846.

22. Rath, B. B.; Vittal, J. J., Dynamic Effects in Crystalline Coordination Polymers. CrystEngComm 2021, https://doi.org/10.1039/D1CE00441G.

23. Naumov, P.; Sahoo, S. C.; Zakharov, B. A.; Boldyreva, E. V., Dynamic single crystals: kinematic analysis of photoinduced crystal jumping (the photosalient effect). Angew. Chem. Int. Ed. 2013, 52 (38), 9990-5.

24. Medishetty, R.; Husain, A.; Bai, Z.; Runčevski, T.; Dinnebier, R. E.; Naumov, P.; Vittal, J. J., Single crystals popping under UV light: a photosalient effect triggered by a [2+ 2] cycloaddition reaction. Angew. Chem. Int. Ed. 2014, 53 (23), 59075911.

25. Seki, T.; Sakurada, K.; Muromoto, M.; Ito, H., Photoinduced single-crystal-to-single-crystal phase transition and photosalient effect of a gold (I) isocyanide complex with shortening of intermolecular aurophilic bonds. Chem. Sci. 2015, 6 (2), 1491-1497.

26. Medishetty, R.; Sahoo, S. C.; Mulijanto, C. E.; Naumov, P. e.; Vittal, J. J., Photosalient behavior of photoreactive crystals. Chem. Mater. 2015, 27 (5), 1821-1829.

27. Mulijanto, C. E.; Quah, H. S.; Tan, G. K.; Donnadieu, B.; Vittal, J. J., Curved crystal morphology, photoreactivity and photosalient behaviour of mononuclear Zn (II) complexes. IUCrJ 2017, 4 (1), 65-71.

28. Hatano, E.; Morimoto, M.; Imai, T.; Hyodo, K.; Fujimoto, A.; Nishimura, R.; Sekine, A.; Yasuda, N.; Yokojima, S.; Nakamura, S., Photosalient phenomena that mimic impatiens are observed in hollow crystals of diarylethene with a perfluorocyclohexene ring. Angew. Chem. Int. Ed. 2017, 56 (41), 12576-12580.

29. Dutta, B.; Sinha, C.; Mir, M. H., The sunlight-driven photosalient effect of a 1D coordination polymer and the release of an elusive cyclobutane derivative. Chem. Commun. 2019, 55 (74), 11049-11051.

30. Yadava, K.; Vittal, J. J., Photosalient behavior of photoreactive Zn (II) complexes. Cryst. Growth Des. 2019, 19 (5), 2542-2547.
31. Yadava, K.; Gallo, G.; Bette, S.; Mulijanto, C. E.; Karothu, D. P.; Park, I.-H.; Medishetty, R.; Naumov, P.; Dinnebier, R. E.; Vittal, J. J., Extraordinary anisotropic thermal expansion in photosalient crystals. IUCrJ 2020, 7 (1), 83-89.

32. Nakagawa, Y.; Morimoto, M.; Yasuda, N.; Hyodo, K.; Yokojima, S.; Nakamura, S.; Uchida, K., Photosalient effect of diarylethene crystals of thiazoyl and thienyl derivatives. Chem. Euro. J. 2019, 25 (33), 7874-7880.

33. Seki, T.; Mashimo, T.; Ito, H., Anisotropic strain release in a thermosalient crystal: correlation between the microscopic orientation of molecular rearrangements and the macroscopic mechanical motion. Chem. Sci. 2019, 10 (15), 4185-4191.

34. Colin-Molina, A.; Karothu, D. P.; Jellen, M. J.; Toscano, R. A.; Garcia-Garibay, M. A.; Naumov, P.; Rodríguez-Molina, B., Thermosalient amphidynamic molecular machines: Motion at the molecular and macroscopic scales. Matter 2019, 1 (4), 1033-1046. 35. Zakharov, B. A.; Michalchuk, A. A.; Morrison, C. A.; Boldyreva, E. V., Anisotropic lattice softening near the structural phase transition in the thermosalient crystal 1, 2, 4, 5tetrabromobenzene. Phys. Chem. Chem. Phys. 2018, 20 (13), 85238532 .

36. Tamboli, M. I.; Karothu, D. P.; Shashidhar, M. S.; Gonnade, R. G.; Naumov, P., Effect of crystal packing on the thermosalient effect of the Pincer-type diester naphthalene-2, 3diyl-bis (4-fluorobenzoate): a new class II thermosalient solid. Chem. - Euro. J. 2018, 24 (16), 4133-4139.

37. So, H.-S.; Minami, T.; Jindo, T.; Matsumoto, S., Thermosalient effect of two polymorphs of a diketopyrrolopyrrole dye with different crystal systems and molecular arrangements. CrystEngComm 2018, 20 (36), 5317-5320.

38. Ohtani, S.; Gon, M.; Tanaka, K.; Chujo, Y., A flexible, fused, azomethine-boron complex: thermochromic luminescence and thermosalient behavior in structural transitions between crystalline polymorphs. Chem. - Euro. J. 2017, 23 (49), 1182711833.

39. Mittapalli, S.; Sravanakumar Perumalla, D.; Nangia, A., Mechanochemical synthesis of N-salicylideneaniline: thermosalient effect of polymorphic crystals. IUCrJ 2017, 4 (3), 243-250.

40. Lončarić, I.; Popović, J.; Despoja, V.; Burazer, S.; Grgičević, I.; Popović, D.; Skoko, Z. e., Reversible thermosalient effect of N'-2-propylidene-4-hydroxybenzohydrazide accompanied by an immense negative compressibility: structural and theoretical arguments aiming toward the elucidation of jumping phenomenon. Cryst. Growth Des. 2017, 17 (8), 4445-4453. 41. Panda, M. K.; Centore, R.; Causà, M.; Tuzi, A.; Borbone, F.; Naumov, P., Strong and anomalous thermal expansion precedes the thermosalient effect in dynamic molecular crystals. Sci. Rep. 2016, 6 (1), 1-11.

42. $\quad$ Panda, M. K.; Runcevski, T.; Husain, A.; Dinnebier, R. E.; Naumov, P., Perpetually self-propelling chiral single crystals. J. Am. Chem. Soc. 2015, 137 (5), 1895-902.

43. Panda, M. K.; Runčevski, T.; Sahoo, S. C.; Belik, A. A.; Nath, N. K.; Dinnebier, R. E.; Naumov, P., Colossal positive and negative thermal expansion and thermosalient effect in a pentamorphic organometallic martensite. Nat. Commun. 2014, 5 (1), 1-8.

44. Sahoo, S. C.; Sinha, S. B.; Kiran, M. S.; Ramamurty, U.; Dericioglu, A. F.; Reddy, C. M.; Naumov, P., Kinematic and mechanical profile of the self-actuation of thermosalient crystal twins of 1,2,4,5-tetrabromobenzene: a molecular crystalline analogue of a bimetallic strip. J Am Chem Soc 2013, 135 (37), 13843-50.

45. Skoko, Z.; Zamir, S.; Naumov, P.; Bernstein, J., The thermosalient phenomenon. "jumping crystals" and crystal chemistry of the anticholinergic agent oxitropium bromide. J. Am. Chem. Soc. 2010, 132 (40), 14191-14202.

46. Annadhasan, M.; Agrawal, A. R.; Bhunia, S.; Pradeep, V. V.; Zade, S. S.; Reddy, C. M.; Chandrasekar, R., Mechanophotonics: Flexible Single-Crystal Organic Waveguides and Circuits. Angew. Chem. Int. Ed. 2020, 59 (33), 13852-13858. 
47. Mei, L.; An, S. w.; Hu, K. q.; Wang, L.; Yu, J. p.; Huang, Z. w.; Kong, X. h.; Xia, C. q.; Chai, Z. f.; Shi, W. q., Molecular Springlike Triple-Helix Coordination Polymers as Dual-Stress and Thermally Responsive Crystalline Metal-Organic Materials. Angew. Chem. Int. Ed. 2020, 59 (37), 16061-16068.

48. Wang, H.; Chen, P.; Wu, Z.; Zhao, J.; Sun, J.; Lu, R., Bending, curling, rolling, and salient behavior of molecular crystals driven by [2+2] cycloaddition of a styrylbenzoxazole derivative. Angew. Chem. Int. Ed. 2017, 56 (32), 9463-9467.

49. Ghosh, S.; Mishra, M. K.; Ganguly, S.; Desiraju, G. R., Dual stress and thermally driven mechanical properties of the same organic crystal: 2, 6-dichlorobenzylidene-4-fluoro-3-nitroaniline. J. Am. Chem. Soc. 2015, 137 (31), 9912-9921.

50. Rath, B. B.; Vittal, J. J., Mechanical Bending and Modulation of Photoactuation Properties in a One-Dimensional Pb (II) Coordination Polymer. Chem. Mater. 2021, 33 (12), 46214627.

51. Chandra Sahoo, S.; Nath, N. K.; Zhang, L.; Semreen, M. H.; Al-Tel, T. H.; Naumov, P., Actuation based on thermo/photosalient effect: a biogenic smart hybrid driven by light and heat. RSC Adv. 2014, 4 (15), 7640-7647.

52. Kato, K.; Seki, T.; Ito, H., (9-Isocyanoanthracene) gold (I) Complexes Exhibiting Two Modes of Crystal Jumps by Different Structure Change Mechanisms. Inorg. Chem. 2021, https://doi.org/10.1021/acs.inorgchem.1c00881.

53. Hean, D.; Alde, L. G.; Wolf, M. O., Photosalient and thermosalient crystalline hemithioindigo-anthracene based isomeric photoswitches. J. Mater. Chem. C 2021, 9, 6789-6795.

54. Gupta, P.; Karothu, D. P.; Ahmed, E.; Naumov, P.; Nath, N. K., Thermally twistable, photobendable, elastically deformable, and self-healable soft crystals. Angew. Chem. Int. Ed. 2018, 57 (28), 8498-8502.

55. Shi, Y. X.; Zhang, W. H.; Abrahams, B. F.; Braunstein, P.; Lang, J. P., Fabrication of photoactuators: Macroscopic photomechanical responses of metal-organic frameworks to irradiation by UV light. Angew. Chem. Int. Ed. 2019, 58 (28), $9453-$ 9458

56. $\quad$ Đaković, M.; Borovina, M.; Pisačić, M.; Aakeröy, C. B.; Soldin, Ž.; Kukovec, B. M.; Kodrin, I., Mechanically Responsive Crystalline Coordination Polymers with Controllable Elasticity. Angew. Chem. Int. Ed. 2018, 57 (45), 14801-14805.

57. Schmidt, G., Photodimerization in the solid state. Pure Appl. Chem. 1971, 27 (4), 647-678.

58. Rath, B. B.; Vittal, J. J., Single-Crystal-to-Single-Crystal [2+ 2] Photocycloaddition Reaction in a Photosalient One-Dimensional Coordination Polymer of Pb (II). J. Am. Chem. Soc. 2020, 142 (47), 20117-20123

59. Sahoo, S. C.; Panda, M. K.; Nath, N. K.; Naumov, P. e., Biomimetic crystalline actuators: structure-kinematic aspects of the self-actuation and motility of thermosalient crystals. J. Am. Chem. Soc. 2013, 135 (33), 12241-12251.

60. Rath, B. B.; Gallo, G.; Dinnebier, R. E.; Vittal, J. J., Reversible Thermosalience in a One-Dimensional Coordination Polymer Preceded by Anisotropic Thermal Expansion and the Shape Memory Effect. J. Am. Chem. Soc. 2021, 143 (4), 2088-2096. 61. Cliffe, M. J.; Goodwin, A. L., PASCal: a principal axis strain calculator for thermal expansion and compressibility determination. J. Appl. Crystallogr. 2012, 45 (6), 1321-1329.

62. Horwitz, L., Studies in cis-and trans-Stilbazoles. J. Org. Chem. 1956, 21 (9), 1039-1041.

63. Bruker, S.-P., Version 6.22 Program for Solution and Refinement of Crystal Structures. Bruker AXS Inc., Madison, Wisconsin, USA 2001. 
For Table of Contents Use Only

Title: Multistimuli Responsive Dynamic Effects in a One-Dimensional Coordination Polymer

Authors: Bibhuti Bhusan Rath, ${ }^{* *}$ Mayank Gupta, ${ }^{\dagger}$ and Jagadese J. Vittal*

\section{Table of Contents Graphics}

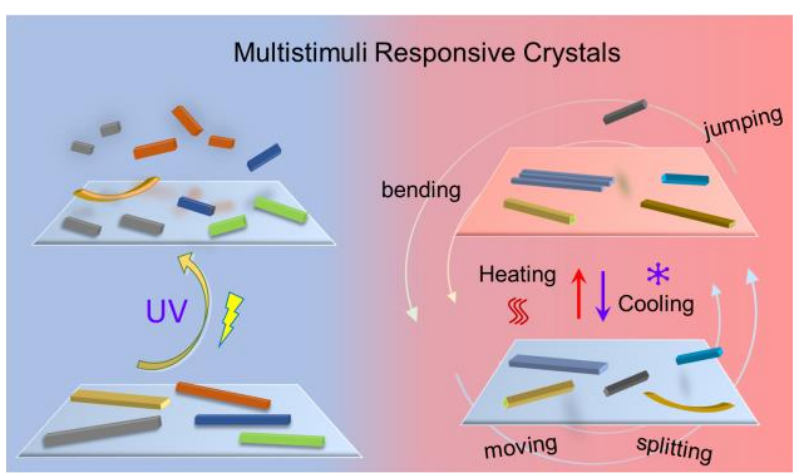




\section{Supporting Information}

\section{Multistimuli Responsive Dynamic Effects in a One-Dimensional Coordination Polymer}

Bibhuti Bhusan Rath, ${ }^{\star \star}$ Mayank Gupta, ${ }^{\dagger}$ and Jagadese J. Vittal ${ }^{\star}$

Department of Chemistry, National University of Singapore, Singapore 117543

Corresponding author: bbrath@u.nus.edu, ijvittal@u.nus.edu

CIF of single crystal 1 (CCDC 2071163)

CIF of single crystal 1a (CCDC 2071164)

CIF of single crystal rctt-2F-ppcb (CCDC 2106246)

Video S1: Photosalient effects

Video S2: Light direction dependant bending

Video S3: Thermosalient effects

Video S4: Thermosalient crystal splitting

Video S5: Elastic bending 


\section{Synthesis and Characterizations}

Preparation of $\left[\mathrm{Pb}(\mathrm{SCN})_{2}(2 \mathrm{~F}-\mathrm{spy})_{2}\right]$, 1: Slow evaporation of a DMF solution containing $\mathrm{Pb}(\mathrm{SCN})_{2}$ $(16.16 \mathrm{mg}, 0.05 \mathrm{mmol})$ and $2 \mathrm{~F}-\mathrm{spy}(20 \mathrm{mg}, 0.1 \mathrm{mmol})$ at a $1: 2$ ratio resulted diffraction quality colourless rod-shaped single crystals within few days. Crystals were filtered and air dried. Yield (79\%). Different ratio of DMF and MeCN were used as crystallization solvents to obtain crystals of different thickness and dimensions. ${ }^{1} \mathrm{H}$ NMR $\left(400 \mathrm{MHz}, 298 \mathrm{~K}, \mathrm{DMSO}-\mathrm{d}_{6}\right): \delta_{\mathrm{H}}=8.57$ (d, 2H, Py-H of 2F-spy), $7.83(\mathrm{~m}, 1 \mathrm{H}, \mathrm{Ph}-\mathrm{H}$ of $2 \mathrm{~F}-\mathrm{spy}), 7.61(\mathrm{~d}, 2 \mathrm{H}, \mathrm{Py}-\mathrm{H}$ of $2 \mathrm{~F}-\mathrm{spy}), 7.58(\mathrm{~d}, 1 \mathrm{H}, \mathrm{HC}=\mathrm{CH}$ of $2 \mathrm{~F}-\mathrm{spy}), 7.41(\mathrm{~m}$, $1 \mathrm{H}, \mathrm{PhH}$ of $2 \mathrm{~F}$-spy), 7.34 (d, $1 \mathrm{H}, \mathrm{HC}=\mathrm{CH}$ of $2 \mathrm{~F}$-spy), $7.30(\mathrm{~m}, 1 \mathrm{H}, \mathrm{PhH}$ of $2 \mathrm{~F}$-spy), $7.27(\mathrm{~m}, 1 \mathrm{H}, \mathrm{PhH}$ of 2F-spy); FT-IR (KBr pellet, $\mathrm{cm}^{-1}$ ): 1636, 1596, 1487, 1441, 1422, 1262, 1226, 1198, 1141, 1063, 995, 954, 858, 803, 774, 727, 674, 588, 540, 509; elemental analysis calcd (\%) for $\mathrm{C}_{28} \mathrm{H}_{20} \mathrm{~F}_{2} \mathrm{~N}_{4} \mathrm{PbS}_{2}$ : C 46.59, H 2.79, N 5.26, S 8.88; found: C 46.53, H 2.72, N 5.26, S 8.81.

Crystal data for 1 at $100(2) \mathrm{K}(\mathrm{CCDC} 2071163): \mathrm{C}_{28} \mathrm{H}_{20} \mathrm{~F}_{2} \mathrm{~N}_{4} \mathrm{PbS}_{2}, \mathrm{M}=721.79$; orthorhombic, $P 2_{1} 2_{1} 2_{1}$; a $=5.8724(2), b=15.6224(4), c=27.6954(8) \AA ; \alpha, \beta, \gamma=90^{\circ} ; V=2540.80(13) \AA^{3} ; Z=4 ; \rho_{\text {calc }}=1.887$ Mg.m $\mathrm{m}^{-3} ; \mu=6.845 \mathrm{~mm}^{-1} ; \mathrm{GOF}=1.151$; final $\mathrm{R}_{1}=0.0133 ; \mathrm{wR}_{2}=0.0285$ [for 7134 data $\mathrm{I}>2 \sigma(\mathrm{I})$ ] and 335 parameters.

Crystal data for $1 \mathrm{a}$ at $393(2) \mathrm{K}(\mathrm{CCDC} 2071164): \mathrm{C}_{28} \mathrm{H}_{20} \mathrm{~F}_{2} \mathrm{~N}_{4} \mathrm{PbS}_{2}, \mathrm{M}=721.79$; orthorhombic, $P 2{ }_{1}{ }_{1}{ }_{2}{ }_{1}$; $a=5.9355(2), b=15.6445(6), c=28.4750(10) \AA ; \alpha, \beta, \gamma=90^{\circ} ; V=2644.13(16) \AA^{3} ; Z=4 ; \rho_{\text {calc }}=1.813$ Mg.m ${ }^{-3} ; \mu=6.578 \mathrm{~mm}^{-1} ;$ GOF $=1.068$; final $\mathrm{R}_{1}=0.0324 ; \mathrm{wR}_{2}=0.0392$ [for 6527 data $\mathrm{I}>2 \sigma(\mathrm{I})$ ] and 335 parameters.

[Pb(SCN $)_{2}$ (rctt-2F-ppcb)], 2: UV irradiation of 1 for 15 min resulted in the formation of 2. As single crystal structure of 2 could not be obtained, the compound was analysed spectroscopically. ${ }^{1} \mathrm{H}$ NMR $\left(400 \mathrm{MHz}, 298 \mathrm{~K}, \mathrm{DMSO}-d_{6}\right): \delta_{\mathrm{H}}=8.35$ (d, 4H, Py-H of rctt-2F-ppcb), $7.42(\mathrm{~m}, 2 \mathrm{H}, \mathrm{Ph}-\mathrm{H}$ of rctt-2Fppcb), 7.27 (d, 4H, Py-H of rctt-2F-ppcb), 7.15 (m, 2H, Ph-H of rctt-2F-ppcb), 7.09 (m, 2H, Ph-H of rctt2F-ppcb), 6.97 (m, 2H, Ph-H of rctt-2F-ppcb), 4.73 (s, 4H, cyclobutane protons of rctt-2F-ppcb); FT-IR $\left(\mathrm{KBr}\right.$ pellet, $\left.\mathrm{cm}^{-1}\right)$ : 1599, 1482, 1447, 1419, 1246, 1229, 1147, 1068, 1004, 876, 831, 805, 788, 719, 683, 537, 510; elemental analysis calcd (\%) for $\mathrm{C}_{28} \mathrm{H}_{20} \mathrm{~F}_{2} \mathrm{~N}_{4} \mathrm{PbS}_{2}$ : C 46.59, H 2.79, N 5.26, S 8.88; found: C 46.50, H 2.71, N 5.23, S 8.79.

rctt-2F-ppcb : UV irradiation of $\mathbf{1}$ for $15 \mathrm{~min}$ resulted in the formation of 2 . The compound lost its crystallinity after $100 \%$ photoconversion. Our attempts to recrystallize 2 were unfruitful. However, an elusive dimerized rctt-2F-ppcb could be obtained after recrystallization in DMSO. ${ }^{1} \mathrm{H}$ NMR $(400 \mathrm{MHz}$, $\left.298 \mathrm{~K}, \mathrm{DMSO}-\mathrm{d}_{6}\right): \delta_{\mathrm{H}}=8.35$ (d, 4H, Py-H of rctt-2F-ppcb), $7.42(\mathrm{~m}, 2 \mathrm{H}, \mathrm{Ph}-\mathrm{H}$ of rctt-2F-ppcb), 7.27 (d, $4 \mathrm{H}$, Py-H of rctt-2F-ppcb), 7.15 (m, 2H, Ph-H of rctt-2F-ppcb), 7.09 (m, 2H, Ph-H of rctt-2F-ppcb), 6.97 (m, 2H, Ph-H of rctt-2F-ppcb), 4.73 (s, 4H, cyclobutane protons of rctt-2F-ppcb); FT-IR (KBr pellet, $\mathrm{cm}^{-}$ $\left.{ }^{1}\right): 1601,1479,1451,1418,1251,1227,1151,1064,999,871,825,804,783,723,682,535,506$; elemental analysis calcd (\%) for $\mathrm{C}_{26} \mathrm{H}_{20} \mathrm{~F}_{2} \mathrm{~N}_{4}$ : C 78.37, H 5.06, N 7.03; found: C 78.32, H 4.99, N 6.96. 


\section{Results and Discussion}

Table S1. Crystallographic information

\begin{tabular}{|c|c|c|c|}
\hline $\begin{array}{l}\text { Compound } \\
\text { CCDC number }\end{array}$ & $\begin{array}{c}1 \\
2071163\end{array}$ & $\begin{array}{c}\mathbf{1 a} \\
2071164\end{array}$ & $\begin{array}{c}\text { rctt-2F-ppcb } \\
2106246\end{array}$ \\
\hline Formula & $\mathrm{C}_{28} \mathrm{H}_{20} \mathrm{~F}_{2} \mathrm{~N}_{4} \mathrm{PbS}_{2}$ & $\mathrm{C}_{28} \mathrm{H}_{20} \mathrm{~F}_{2} \mathrm{~N}_{4} \mathrm{PbS}_{2}$ & $\mathrm{C}_{26} \mathrm{H}_{20} \mathrm{~F}_{2} \mathrm{~N}_{2}$ \\
\hline Formula weight & 721.79 & 721.79 & 398.44 \\
\hline Crystal system & orthorhombic & orthorhombic & orthorhombic \\
\hline Space Group & $P 2_{1} 2_{1} 2_{1}$ & $P 2_{1} 2_{1} 2_{1}$ & Pca2 $_{1}$ \\
\hline $\mathrm{a}(\AA)$ & $5.8724(2)$ & $5.9355(2)$ & $11.2373(4)$ \\
\hline $\mathrm{b}(\AA)$ & $15.6224(4)$ & $15.6445(6)$ & $11.6894(5)$ \\
\hline$c(\AA)$ & $27.6954(8)$ & $28.475(1)$ & $15.0288(6)$ \\
\hline$\alpha, \beta, \gamma\left(^{\circ}\right)$ & 90 & 90 & 90 \\
\hline$V\left(\AA^{3}\right)$ & $2540.80(13)$ & $2644.13(16)$ & $1974.14(14)$ \\
\hline Z & 4 & 4 & 4 \\
\hline$\rho_{\text {call }}, \mathrm{Mg} / \mathrm{m}^{3}$ & 1.887 & 1.813 & 1.341 \\
\hline$\mu, \mathrm{mm}^{-1}$ & 6.845 & 6.578 & 0.092 \\
\hline $\mathrm{T}(\mathrm{K})$ & $100(2)$ & $393(2)$ & $100(2)$ \\
\hline $\mathrm{R}_{1}$ & 0.0180 & 0.0226 & 0.1045 \\
\hline $\mathrm{wR}_{2}$ & 0.0357 & 0.0392 & 0.2444 \\
\hline GOF & 1.067 & 1.068 & 1.022 \\
\hline $\begin{array}{l}\text { Total no. of unique } \\
\text { data }\end{array}$ & 7134 & 6527 & 11432 \\
\hline Flack Parameter, x & $-0.009(2)$ & $0.008(4)$ & $0.1(6)$ \\
\hline
\end{tabular}




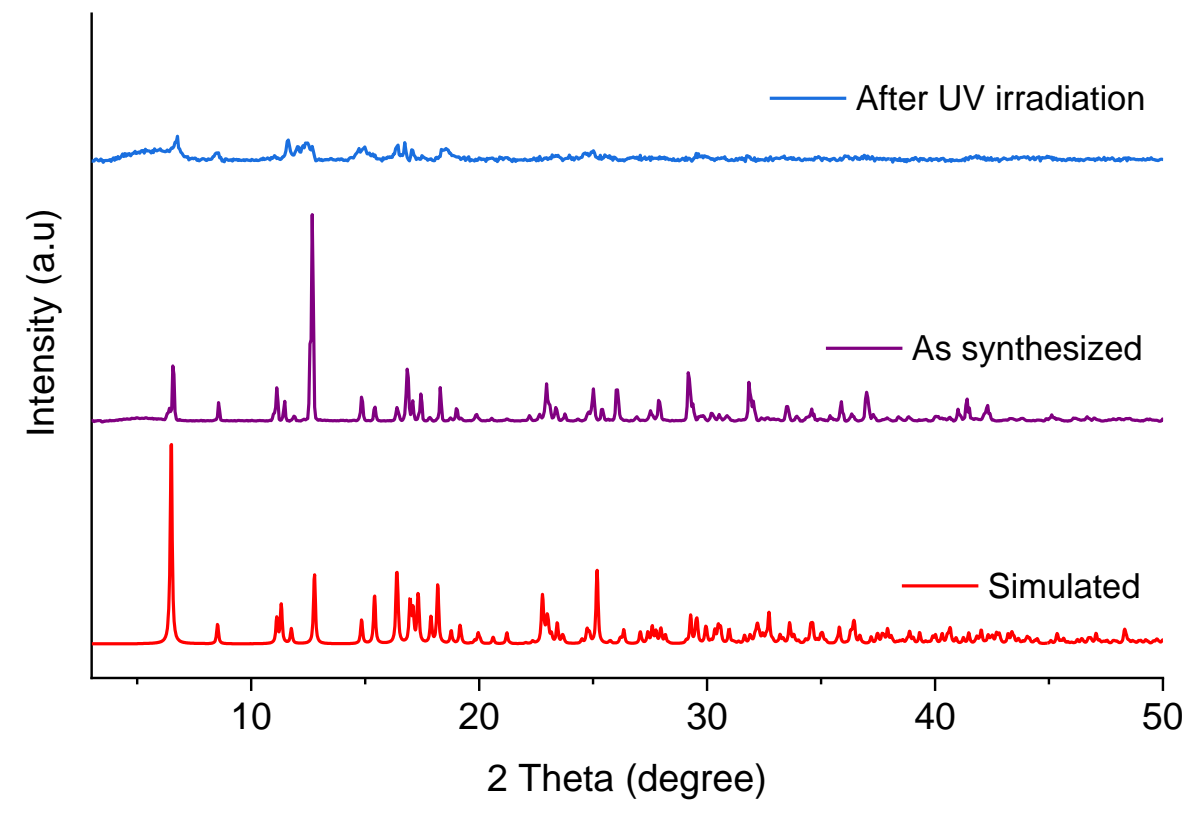

Figure S1. Comparison of PXRD patterns of as synthesized $\mathbf{1}$ and $\mathbf{1}$ after UV irradiation (2) with the simulated pattern of 1.

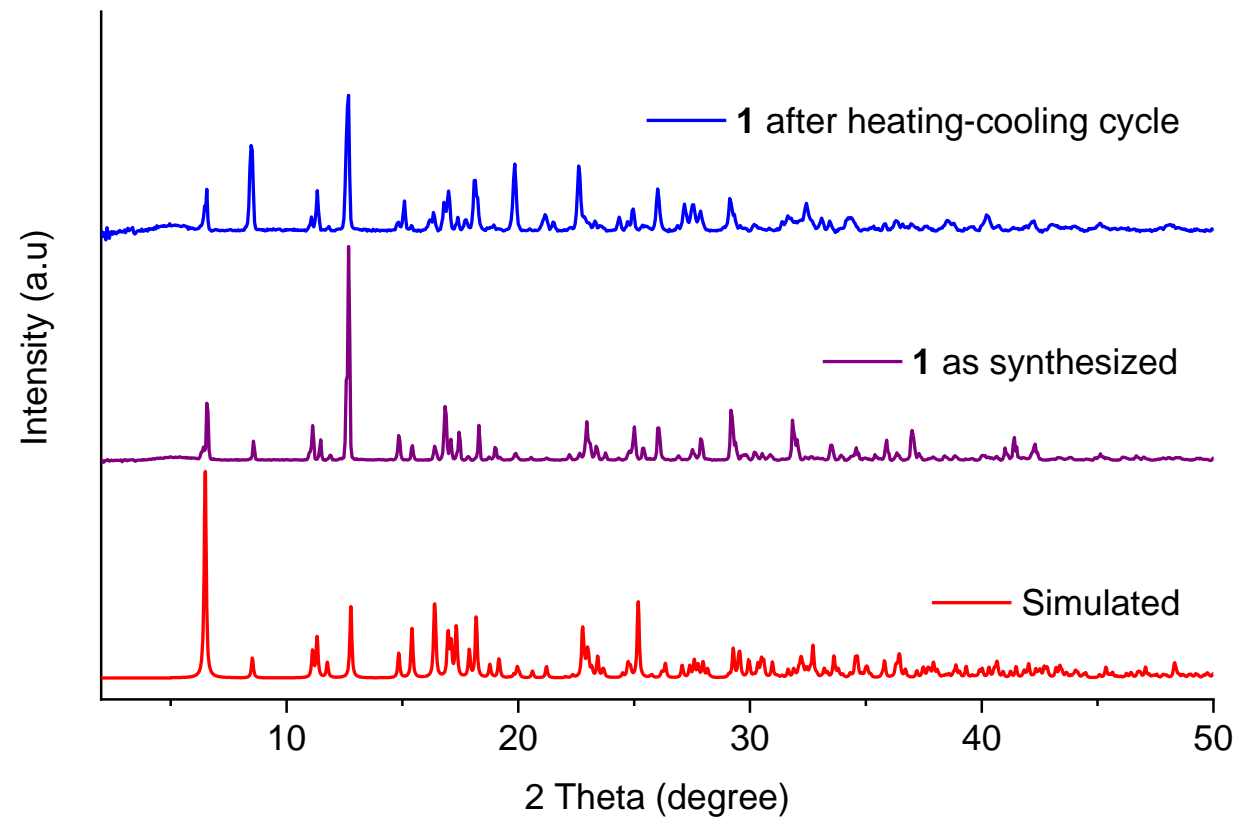

Figure S2. Comparison of PXRD patterns of as synthesized 1 and 1 after heating-cooling cycles with the simulated pattern of $\mathbf{1}$. 


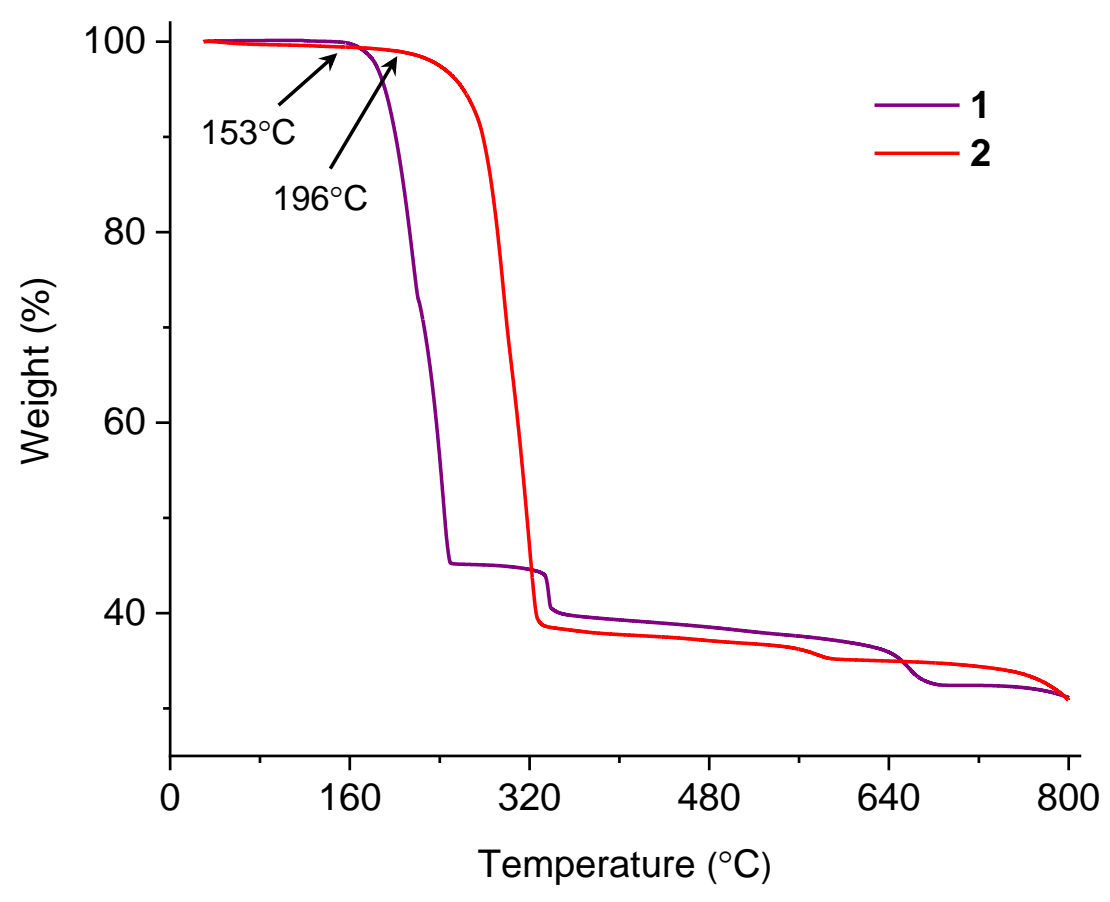

Figure S3. TGA curves for compound $\mathbf{1}$ and $\mathbf{2}$. The thermal stability of $\mathbf{2}$ is higher than that of $\mathbf{1}$.

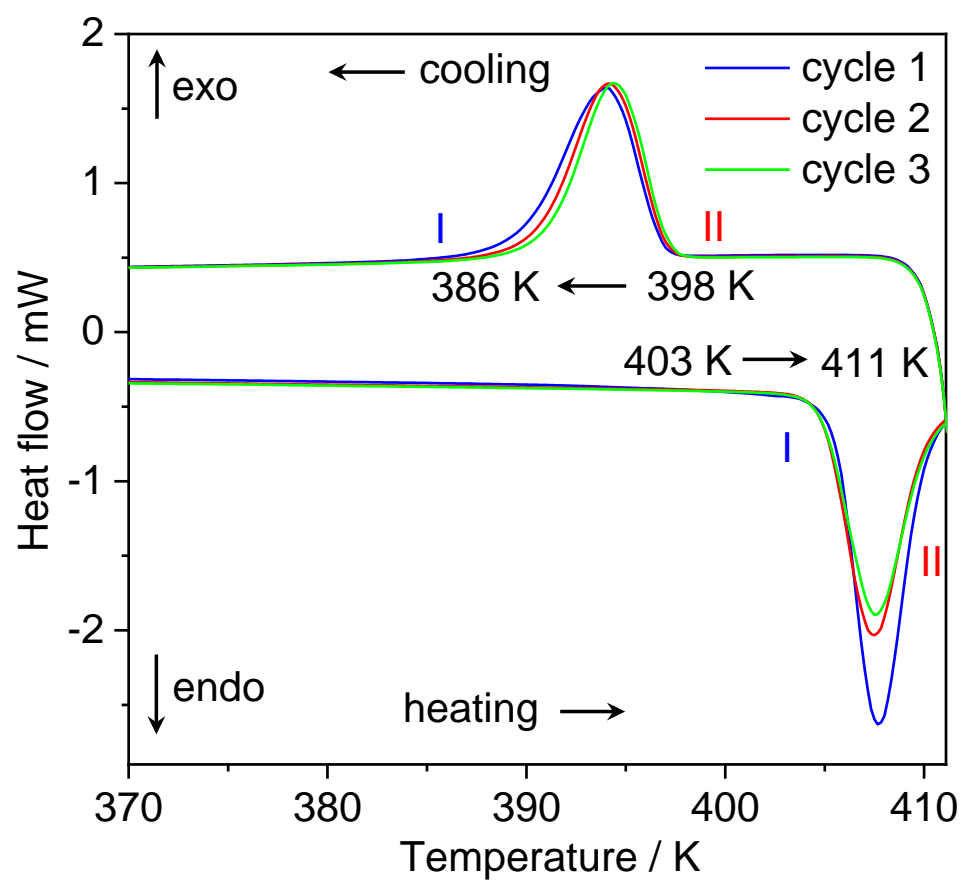

Figure S4. DSC curves for powder sample of $\mathbf{1}$ for three consecutive heating-cooling cycles at heating/cooling rate $5 \mathrm{~K} \mathrm{~min}^{-1}$. 


\section{Single crystal structures}

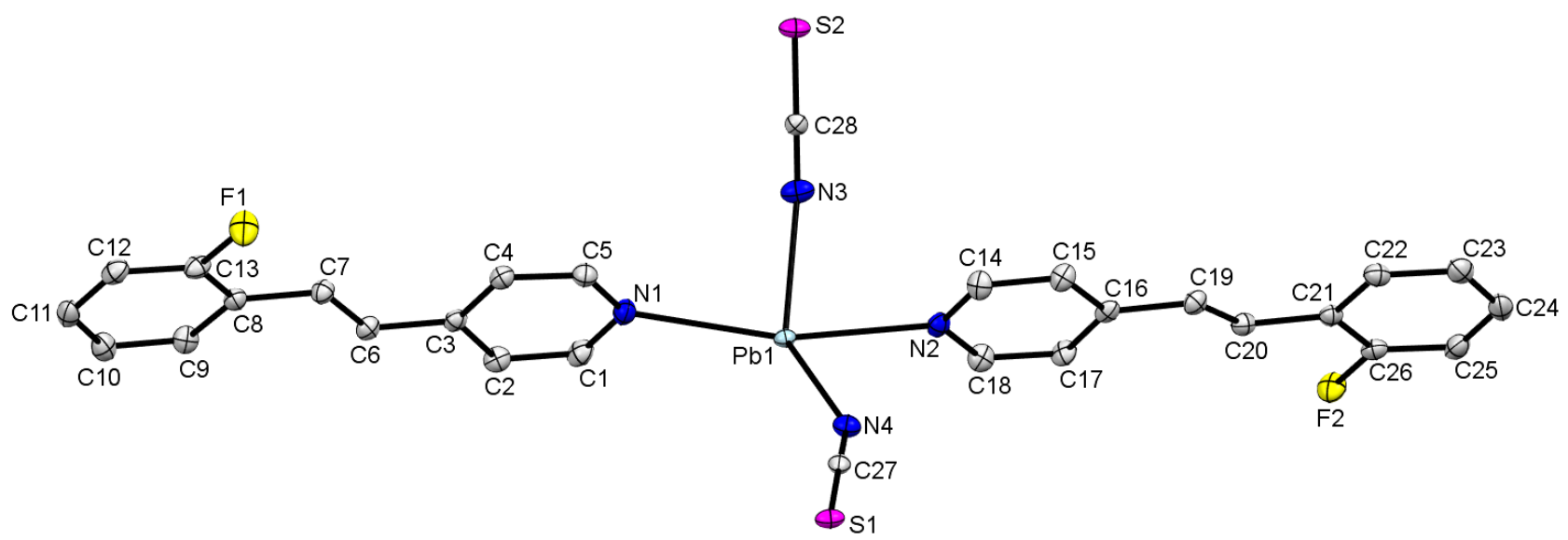

Figure S5. The asymmetric unit of 1 is shown with the numbering scheme.

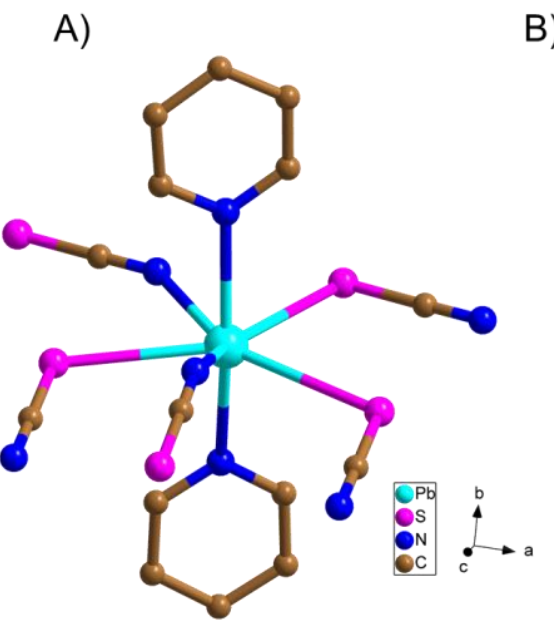

B)

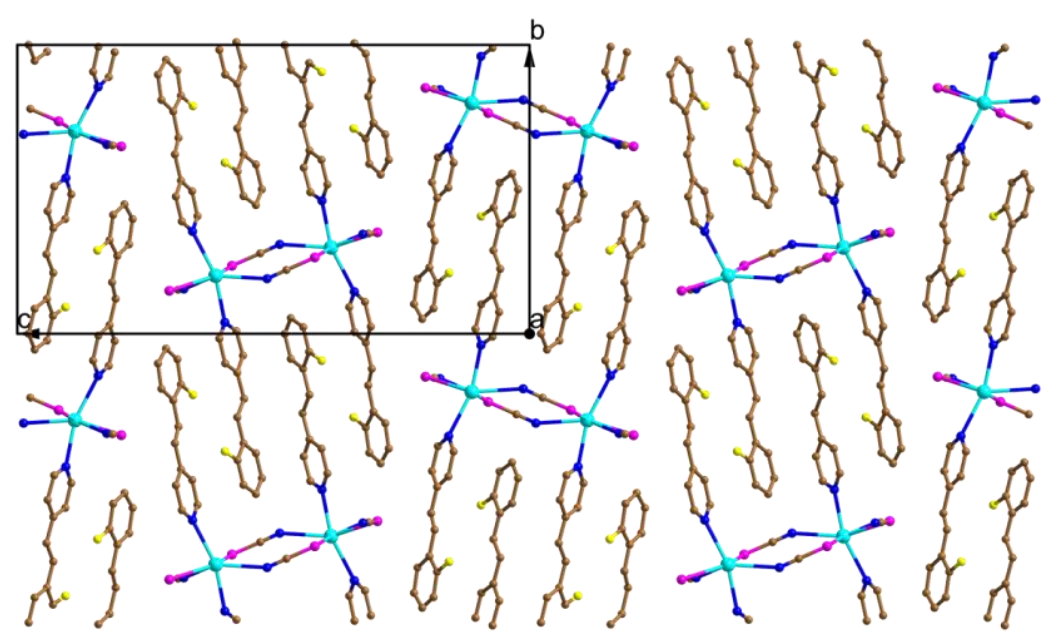

Figure S6. (A) Coordination environment around $\mathrm{Pb}$ atom and (B) Crystal structure of 1 viewed along the a-axis. 


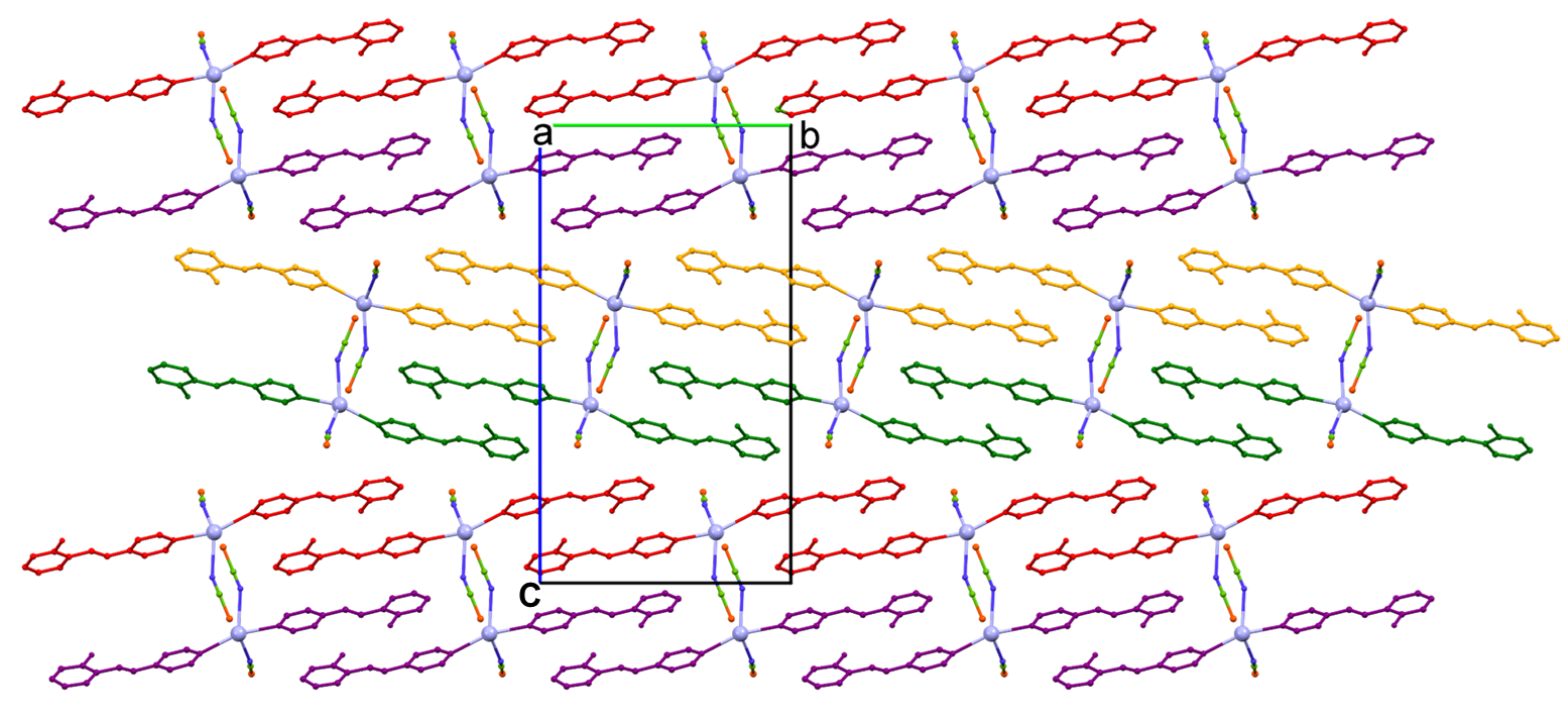

Figure S7. Crystal structure of 1 viewed along the a-axis showing four different orientation for the formation of cyclobutane product.

A)

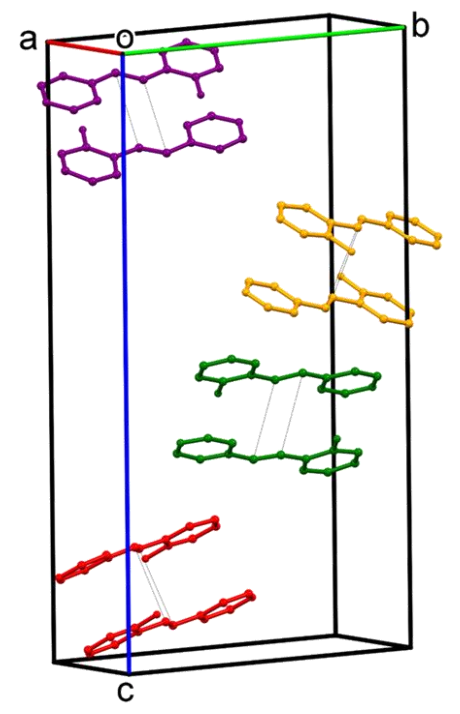

B)

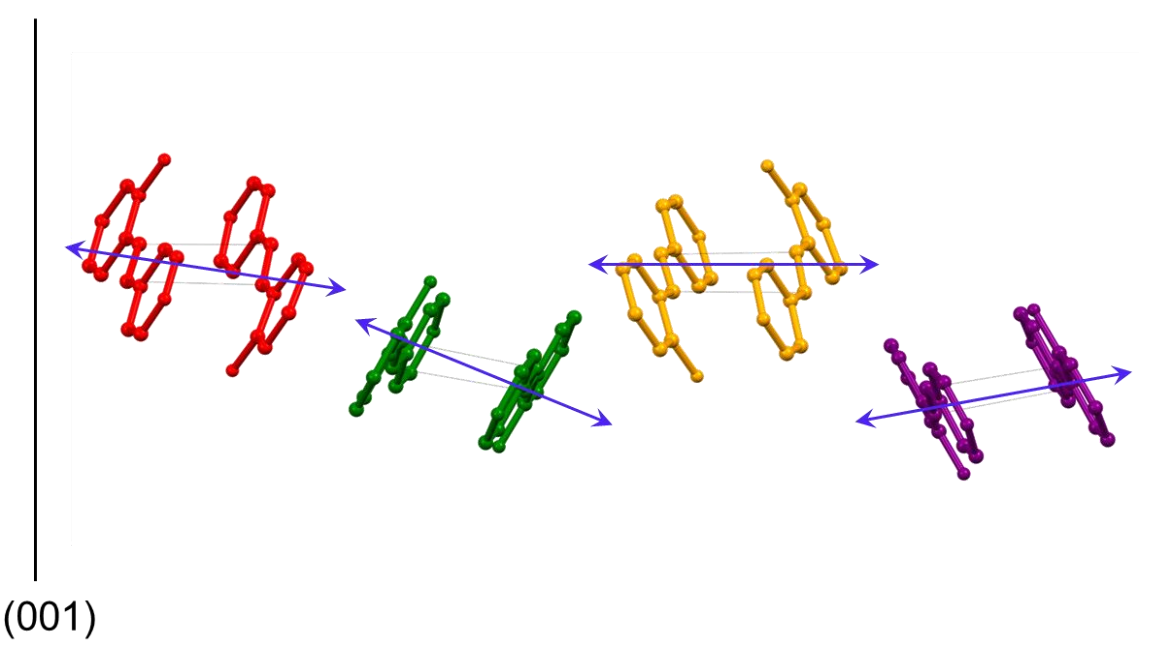

Figure S8. Crystal structure of $\mathbf{1}$ showing four different orientation for the formation of cyclobutane product with respect to the (001) plane i.e the largest crystal face. 
a)

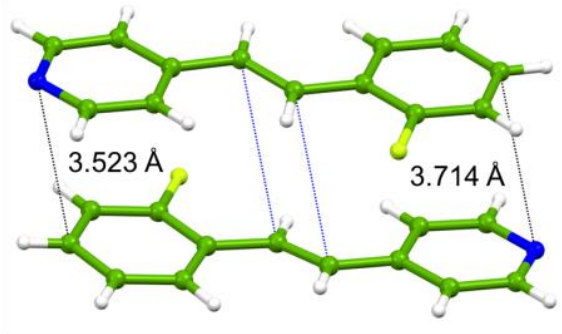

b)

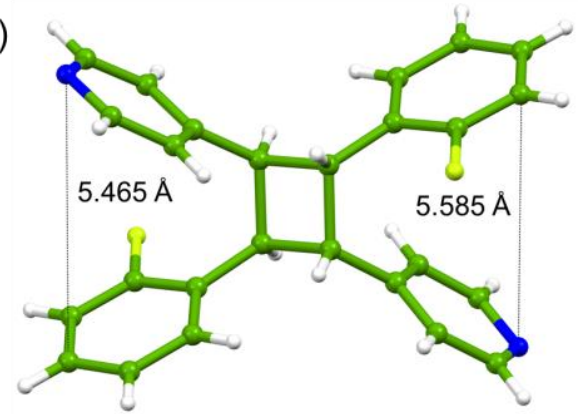

Figure S9. Comparison between (a) aligned 2F-spy ligands in $\mathbf{1}$ and (b) isolated dimerized rctt-2Fppcb.

a)

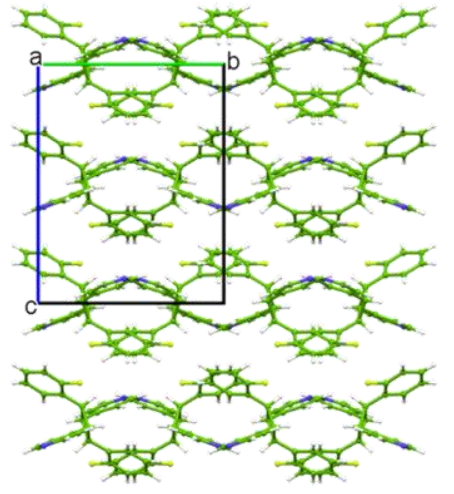

b)

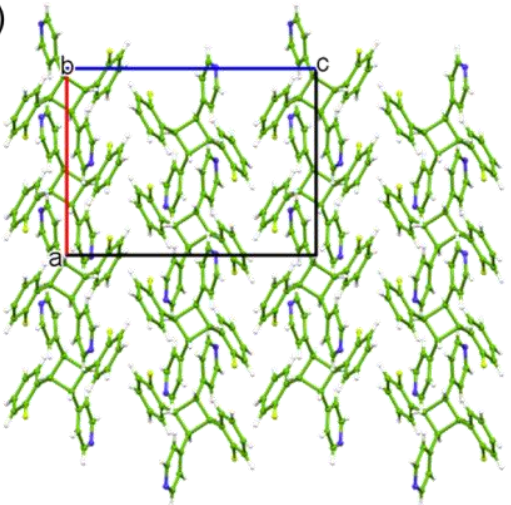

c)

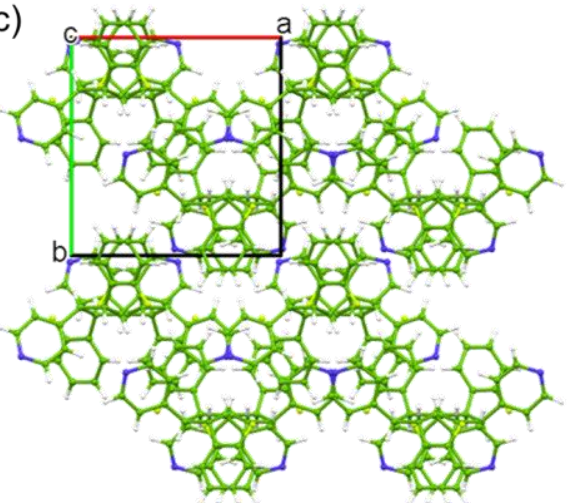

Figure S10. Single crystal structure of rctt-2F-ppcb and crystal packing viewed along $a$-, $b$ - and $c$-axis.

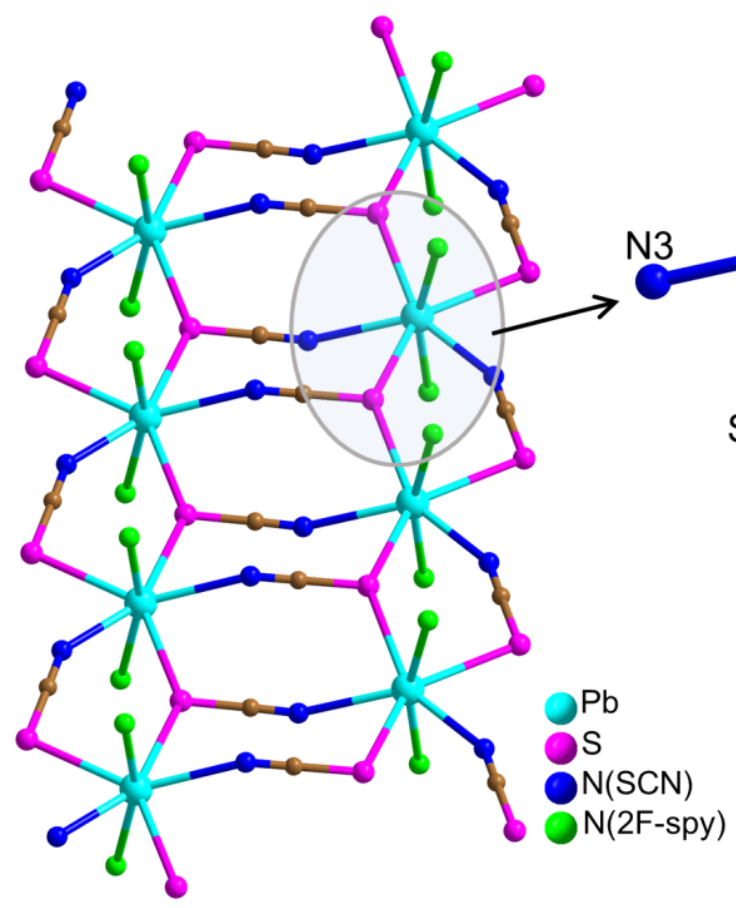

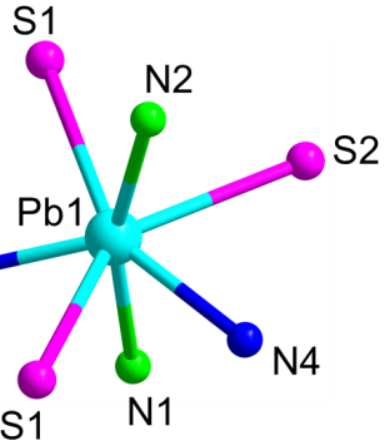

\begin{tabular}{|ccc|}
\hline $\begin{array}{c}\text { Bond } \\
\text { distances }\end{array}$ & $\begin{array}{c}\mathbf{1} \\
(\mathbf{A})\end{array}$ & $\begin{array}{c}\mathbf{1 a} \\
(\mathbf{A})\end{array}$ \\
\hline $\mathrm{Pb} 1 \ldots \mathrm{N} 1$ & 2.707 & 2.724 \\
$\mathrm{~Pb} 1 \ldots \mathrm{N} 2$ & 2.576 & 2.588 \\
$\mathrm{~Pb} 1 \ldots \mathrm{N} 3$ & 2.519 & 2.534 \\
$\mathrm{~Pb} 1 \ldots \mathrm{N} 4$ & 2.787 & 2.807 \\
$\mathrm{~Pb} 1 \ldots \mathrm{S} 1$ & 3.188 & 3.214 \\
$\mathrm{~Pb} 1 \ldots \mathrm{S} 2$ & 3.02 & 3.047 \\
$\mathrm{~Pb} 1 \ldots \mathrm{S} 1$ & 3.041 & 3.104 \\
\hline
\end{tabular}

\begin{tabular}{|ccc|}
\hline $\begin{array}{c}\text { Bond } \\
\text { angles } \angle\end{array}$ & $\begin{array}{c}\mathbf{1} \\
\left.\mathbf{(}^{\circ}\right)\end{array}$ & $\begin{array}{c}\text { 1a } \\
\left.\mathbf{(}^{\circ}\right)\end{array}$ \\
\hline $\mathrm{N} 1 \mathrm{~Pb} 1 \mathrm{~N} 2$ & 162.5 & 163.13 \\
$\mathrm{~N} 1 \mathrm{~Pb} 1 \mathrm{~N} 4$ & 120.94 & 119.69 \\
$\mathrm{~N} 1 \mathrm{~Pb} 1 \mathrm{~N} 3$ & 84.6 & 85.09 \\
$\mathrm{~N} 2 \mathrm{~Pb} 1 \mathrm{~N} 4$ & 75.54 & 76.69 \\
$\mathrm{~N} 2 \mathrm{~Pb} 1 \mathrm{~N} 3$ & 79.1 & 80.1 \\
$\mathrm{~N} 4 \mathrm{~Pb} 1 \mathrm{~N} 3$ & 132.3 & 132.25 \\
$\mathrm{~S} 2 \mathrm{~Pb} 1 \mathrm{~S} 1$ & 138.61 & 140.16 \\
$\mathrm{~N} 1 \mathrm{~Pb} 1 \mathrm{~S} 1$ & 86.14 & 86.76 \\
$\mathrm{~N} 1 \mathrm{~Pb} 1 \mathrm{~S} 2$ & 83.04 & 83.01 \\
$\mathrm{~N} 3 \mathrm{~Pb} 1 \mathrm{~S} 1$ & 67.46 & 67.27 \\
$\mathrm{~N} 3 \mathrm{~Pb} 1 \mathrm{~S} 2$ & 71.81 & 73.54 \\
$\mathrm{~N} 4 \mathrm{~Pb} 1 \mathrm{~S} 1$ & 74.51 & 73.79 \\
$\mathrm{~N} 4 \mathrm{~Pb} 1 \mathrm{~S} 2$ & 143.56 & 143.30 \\
\hline
\end{tabular}

Figure S11. Comparison of bond distances and bond angles between 1 (100 K) and 1a (393 K) showing the flexibilty of $\mathrm{Pb}_{3}(\mathrm{SCN})_{3}$ units in the corrugated 1D chains. 
Face indexing of crystal

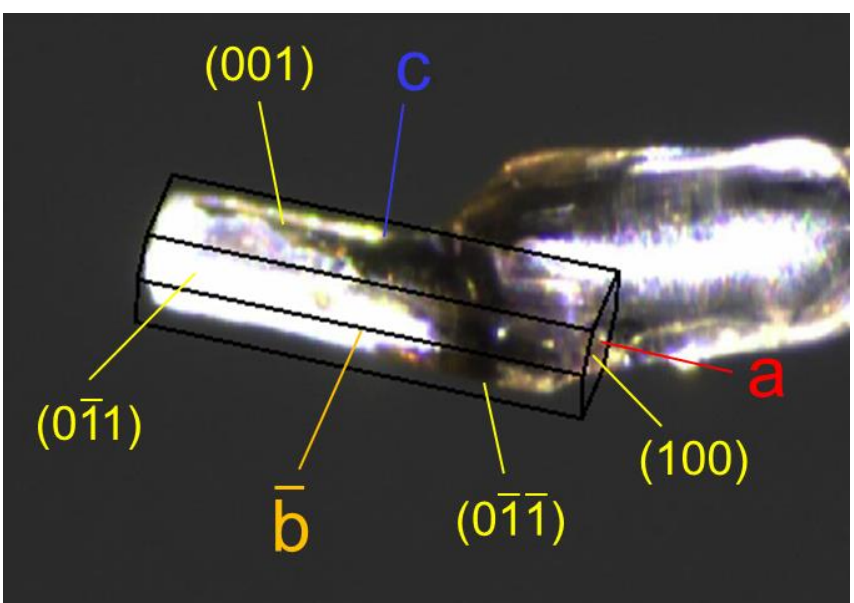

Figure S12. Face indexing of a single crystal of 1 (295 K) showing axes directions and different planes.

\section{Photomechanical experiments}

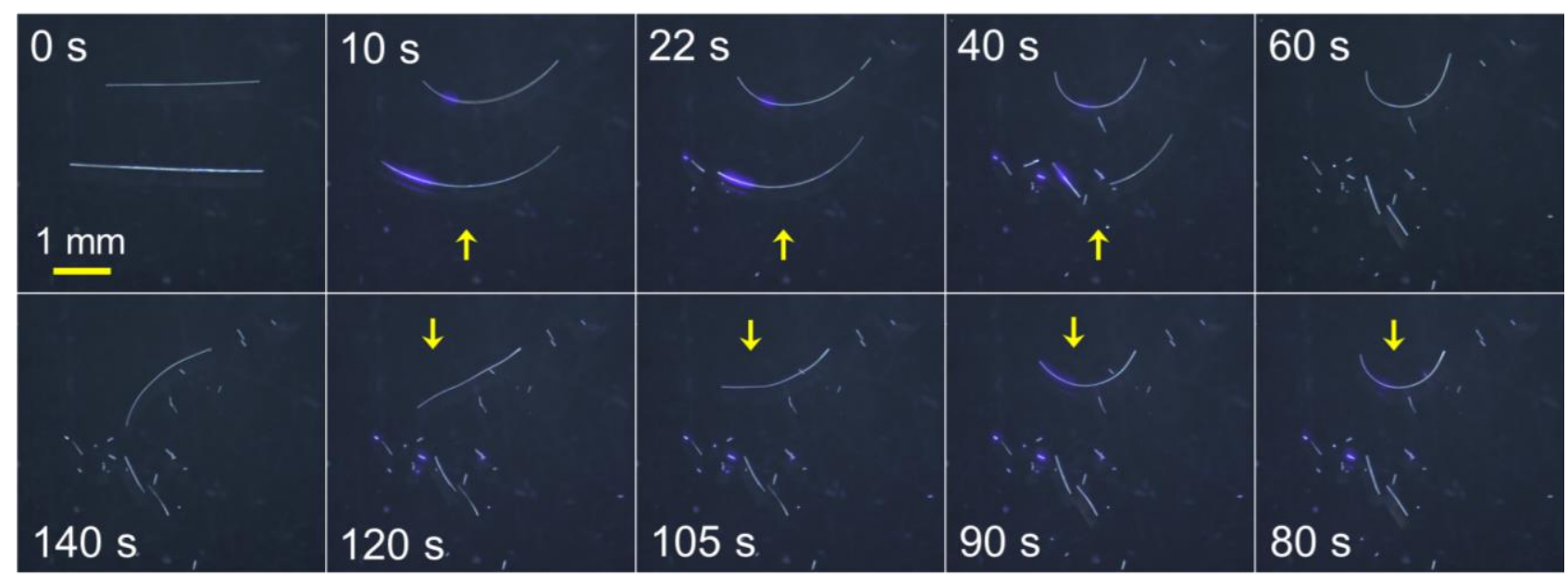

Figure S13. Images of a slender crystal of 1 shows movement during UV irradiation. The crystal moved/bent away from the light source and it can be reversed by changing the light direction (the arrows indicate the irradiation direction). 


\section{Thermosalient experiments}

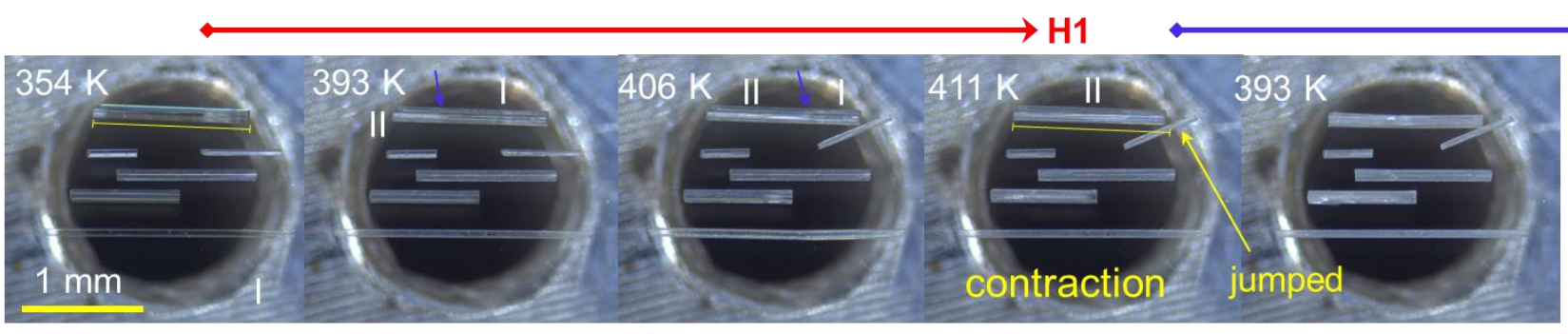

$\mathrm{C} 7 \longleftrightarrow \mathrm{H} 7 \longleftrightarrow \mathrm{C} 3 \longleftrightarrow \mathrm{H} 2 \longleftrightarrow \quad \longleftrightarrow$

C1

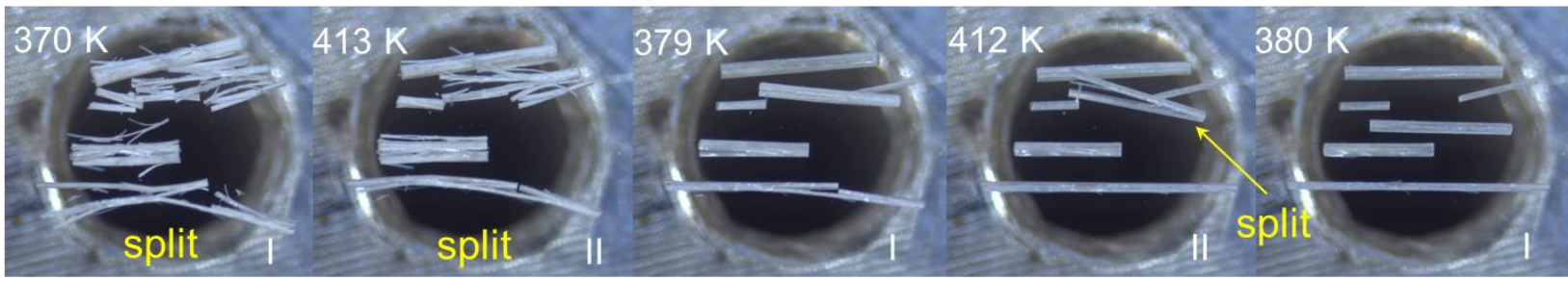

Figure S14. Heating/cooling stage microscopy images of single crystals of 1 showing multiple splitting, jumping during seven consecutive heating/cooling cycles. The heating/cooling rate was $5 \mathrm{~K} \mathrm{~min}^{-1}$.

Table S2. Weak interactions in 1 and 1a.

\begin{tabular}{|l|l|l|l|l|}
\hline $\mathrm{D}-\mathrm{H} \cdots \mathrm{A}$ & $\begin{array}{c}d(\mathrm{D}-\mathrm{H}) \\
/ \AA\end{array}$ & $\begin{array}{c}d(\mathrm{H} \cdots \mathrm{A}) \\
/ \AA\end{array}$ & $\begin{array}{c}d(\mathrm{D} \cdots \mathrm{A}) \\
/ \AA\end{array}$ & $\begin{array}{c}\angle(\mathrm{D}-\mathrm{H} \cdots \mathrm{A}) \\
/ \circ\end{array}$ \\
\hline $\mathrm{C} 4-\mathrm{H} 4 \cdots \mathrm{F} 2(\mathrm{C} 26)$ & 0.95 & 2.580 & 3.465 & 154.06 \\
\hline $\mathrm{C} 17-\mathrm{H} 17 \cdots \mathrm{F} 1(\mathrm{C} 13)$ & 0.95 & 2.434 & 3.318 & 155.53 \\
\hline $\mathrm{C} 6-\mathrm{H} 6 \cdots \mathrm{S} 2$ & 0.95 & 3.195 & 4.033 & 148.15 \\
\hline $\mathrm{C} 2-\mathrm{H} 2 \cdots \mathrm{H} 10-\mathrm{C} 10$ & 0.95 & 2.480 & & \\
\hline $\mathrm{C} 4-\mathrm{H} 4 \cdots \mathrm{F} 2(\mathrm{C} 26)$ & 0.93 & 2.675 & 3.539 & 154.98 \\
\hline $\mathrm{C} 17-\mathrm{H} 17 \cdots \mathrm{F} 1(\mathrm{C} 13)$ & 0.93 & 2.522 & 3.393 & 155.82 \\
\hline $\mathrm{C} 6-\mathrm{H} 6 \cdots \mathrm{S} 2$ & 0.93 & 3.311 & 4.152 & 151.51 \\
\hline $\mathrm{C} 2-\mathrm{H} 2 \cdots \mathrm{H} 10-\mathrm{C} 10$ & 0.93 & 2.480 & & \\
\hline
\end{tabular}




\section{Thermal expansion calculation from variable temperature SCXRD}

Data analysed from $173 \mathrm{~K}$ to $393 \mathrm{~K}$ for calculation of thermal expansion.
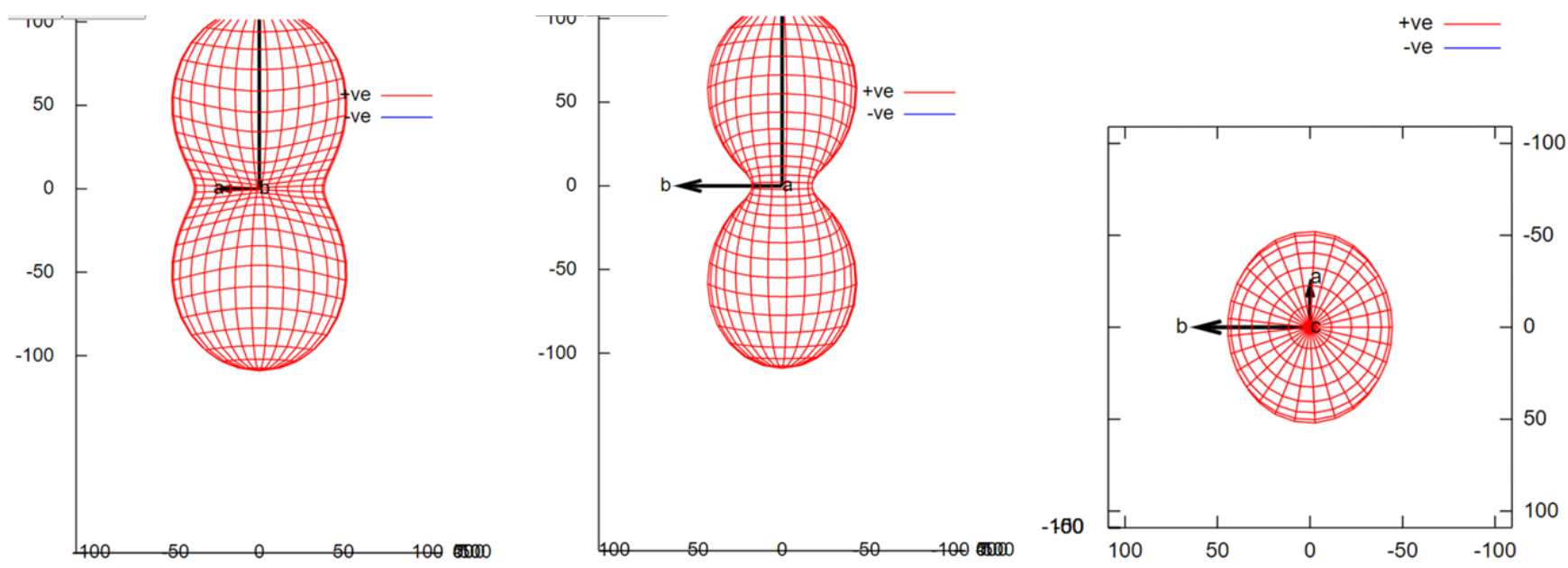

Figure S15. Plots showing expansivity indicatrices along the principal axes (units: $10^{-6} \mathrm{~K}^{-1}$ ) for $\mathbf{1}$.

Table S3. Volume expansion coefficients and all axes expansion coefficients for $\mathbf{1}$ using the program PASCal. ${ }^{1}$

\begin{tabular}{|l|l|l|c|c|c|}
\hline \multicolumn{2}{|c|}{} & \multicolumn{3}{|c|}{ Direction } \\
\hline \multicolumn{1}{|c|}{ Axes } & \multicolumn{1}{|c|}{$\alpha\left(10^{-6} \mathrm{~K}^{-1}\right)$} & $\sigma_{\alpha}\left(10^{-6} \mathrm{~K}^{-1}\right)$ & $a$ & $b$ & $c$ \\
\hline$X_{1}$ & 11.8575 & 0.6252 & 0 & 1 & 0 \\
\hline$X_{2}$ & 38.6900 & 1.5056 & 1 & 0 & 0 \\
\hline$X_{3}$ & 109.0696 & 2.4679 & 0 & 0 & 1 \\
\hline $\mathrm{V}$ & 161.9953 & 3.0895 & \multicolumn{4}{|c|}{} \\
\hline
\end{tabular}

$\alpha$ is the linear coefficient of thermal expansion, $\sigma_{\alpha}$ is the error in the linear coefficient of thermal expansion, $a, b$ and $c$ are the projections of $X_{n}$ on the unit cell axes. 


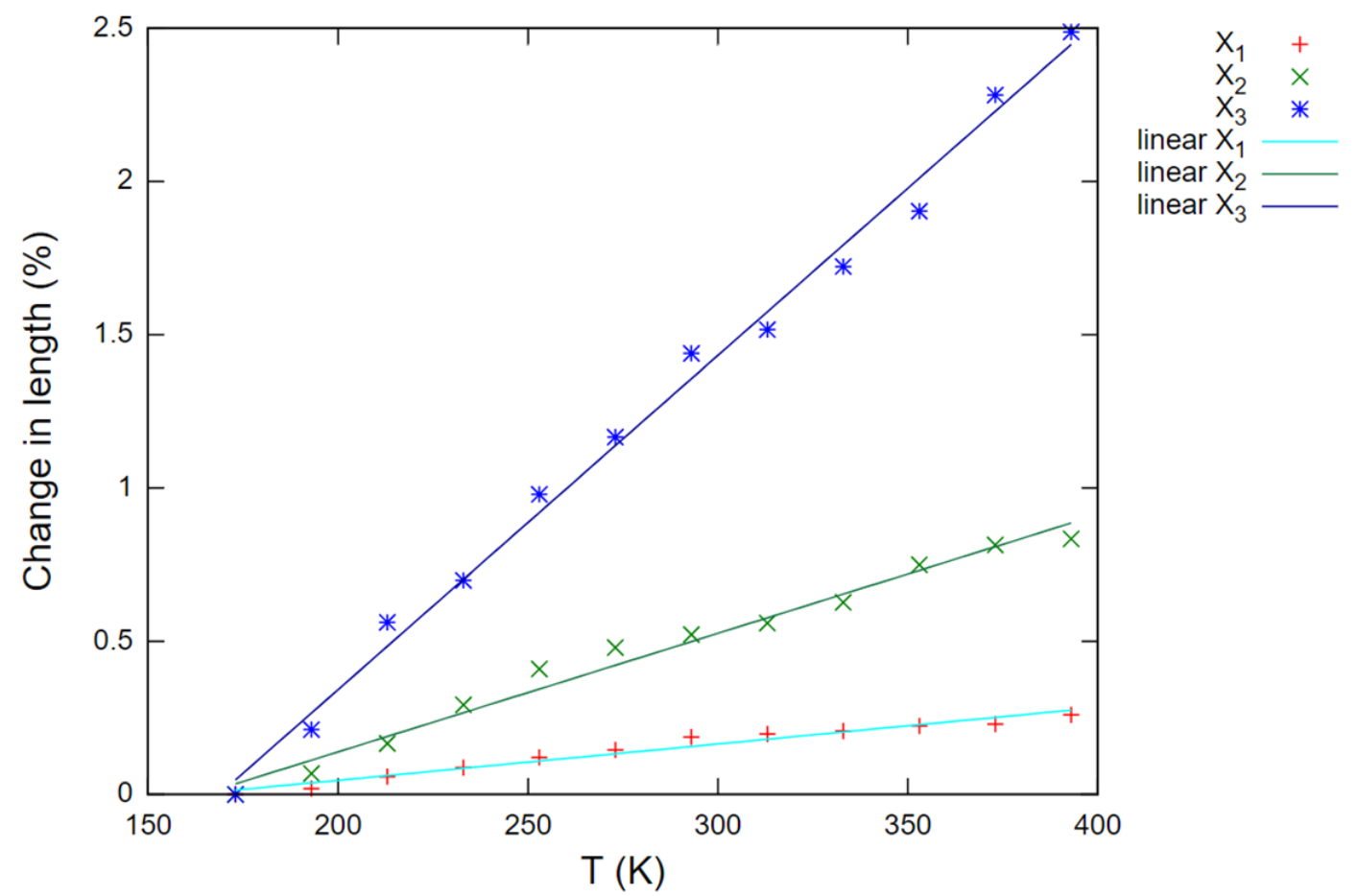

Figure S16. Thermal expansions along the principal axes are linear in the measured temperature range $173 \mathrm{~K}$ to $393 \mathrm{~K}$.

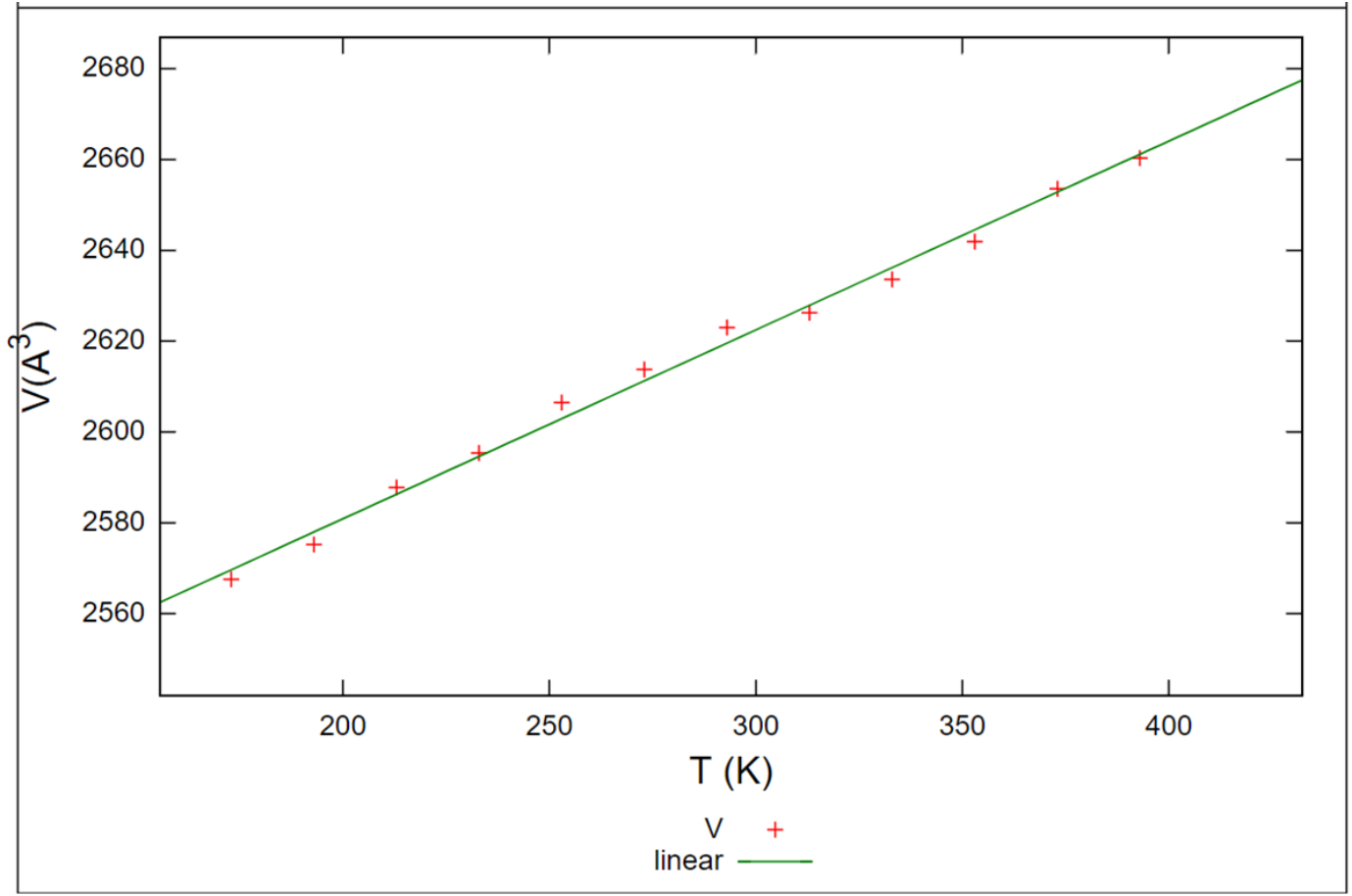

Figure S17. A plot of volume vs temperature shows the overall thermal expansion of volume in 1. 
Table S4. Variable temperature SCXRD data used for calculating the thermal expansion coefficients of 1 between 173 to $393 \mathrm{~K}$.

\begin{tabular}{|cccccccc|}
\hline $\mathbf{T}(\mathbf{K})$ & $\mathbf{\sigma} \mathbf{T}$ & $\mathbf{a}(\mathbf{\AA})$ & $\mathbf{b}(\AA)$ & $\mathbf{c}(\AA)$ & $\mathbf{\alpha}\left(^{\circ}\right)$ & $\boldsymbol{\beta}\left(^{\circ}\right)$ & $\mathbf{Y}\left(^{\circ}\right)$ \\
\hline 173 & 2 & 5.8864 & 15.6388 & 27.8915 & 90 & 90 & 90 \\
193 & 2 & 5.8904 & 15.6417 & 27.9504 & 90 & 90 & 90 \\
213 & 2 & 5.8962 & 15.6479 & 28.0481 & 90 & 90 & 90 \\
233 & 2 & 5.9036 & 15.6525 & 28.0863 & 90 & 90 & 90 \\
253 & 2 & 5.9105 & 15.6577 & 28.1645 & 90 & 90 & 90 \\
273 & 2 & 5.9146 & 15.6615 & 28.2167 & 90 & 90 & 90 \\
293 & 2 & 5.9171 & 15.6681 & 28.2928 & 90 & 90 & 90 \\
313 & 2 & 5.9193 & 15.6697 & 28.3144 & 90 & 90 & 90 \\
333 & 2 & 5.9233 & 15.6711 & 28.3719 & 90 & 90 & 90 \\
353 & 2 & 5.9305 & 15.6738 & 28.4222 & 90 & 90 & 90 \\
373 & 2 & 5.9343 & 15.6746 & 28.5278 & 90 & 90 & 90 \\
393 & 2 & 5.9355 & 15.6795 & 28.5853 & 90 & 90 & 90 \\
\hline
\end{tabular}

Table S5. Selected cell parameters of single crystal of 1a before and after thermosalient phase transition during heating.

\begin{tabular}{lcc}
\hline Compound & $\begin{array}{c}\text { Phase I } \\
(393 \mathbf{K})\end{array}$ & $\begin{array}{c}\text { Phase II } \\
(\mathbf{4 0 8} \text { K) }\end{array}$ \\
\hline Formula & $\mathrm{C}_{28} \mathrm{H}_{20} \mathrm{~F}_{2} \mathrm{~N}_{4} \mathrm{PbS}_{2}$ & $\mathrm{C}_{28} \mathrm{H}_{20} \mathrm{~F}_{2} \mathrm{~N}_{4} \mathrm{PbS}_{2}$ \\
Formula weight & 721.79 & 721.79 \\
Crystal system & orthorhombic & orthorhombic \\
Space Group & $P 2{ }_{1} 2_{1}$ & $P 2{ }_{1}{ }_{1} 2_{1}$ \\
a $(\AA)$ & $5.9355(2)$ & $5.8025(7)$ \\
b $(\AA)$ & $15.6445(6)$ & $15.6635(9)$ \\
c $(\AA)$ & $28.4750(10)$ & $30.3802(11)$ \\
V $\left(\AA^{3}\right)$ & $2644.13(16)$ & $2761.17(14)$ \\
Z & 4 & 4 \\
T $(\mathrm{K})$ & $393(2)$ & $408(2)$
\end{tabular}


Table S6. Selected cell parameters of single crystals during repeated bending experiments.

\begin{tabular}{|l|l|l|l|l|}
\hline \multirow{2}{*}{$\begin{array}{l}\text { Data } \\
\text { 293(2) K }\end{array}$} & \multicolumn{2}{|c|}{ Crystal i } & \multicolumn{2}{c|}{ Crystal ii } \\
\cline { 2 - 5 } & Before bending & After bending & Before bending & After bending \\
\hline a $(\AA)$ & $5.9169(8)$ & $5.9244(10)$ & $5.9125(7)$ & $5.9239(10)$ \\
\hline b $(\AA)$ & $15.6678(6)$ & $15.6807(13)$ & $15.6805(11)$ & $15.6712(6)$ \\
\hline c $(\AA)$ & $28.2923(9)$ & $28.2948(4)$ & $28.3087(2)$ & $28.3175(4)$ \\
\hline$\alpha, \beta, \gamma\left(^{\circ}\right)$ & 90 & 90 & 90 & 90 \\
\hline$V\left(\AA^{3}\right)$ & $2622.8321(5)$ & $2628.5512(3)$ & $2624.5266(7)$ & $2628.8443(2)$ \\
\hline
\end{tabular}

\section{Reference}

[1] Cliffe, M. J.; Goodwin, A. L. J. Appl. Crystallogr., 2012, 45, 1321-1329. 